\title{
Pharmacokinetic and Pharmacodynamic Properties of Canakinumab, a Human Anti-Interleukin-1及 Monoclonal Antibody
} \author{
and Sandip Roy ${ }^{2}$ \\ 1 Novartis Institutes for BioMedical Research, East Hanover, NJ, USA \\ 2 Novartis Pharmaceuticals Corporation, East Hanover, NJ, USA \\ 3 Novartis Pharma AG, Postfach, Basel, Switzerland
}

Abhijit Chakraborty, ${ }^{1}$ Stacey Tannenbaum, ${ }^{2}$ Christiane Rordorf, ${ }^{3}$ Philip J. Lowe, ${ }^{3}$ David Floch, ${ }^{3}$ Hermann Gram ${ }^{3}$

\section{Contents}

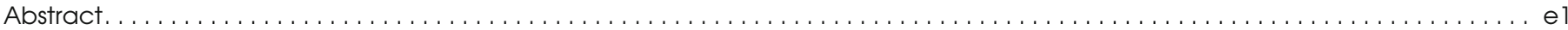

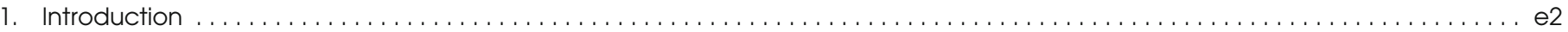

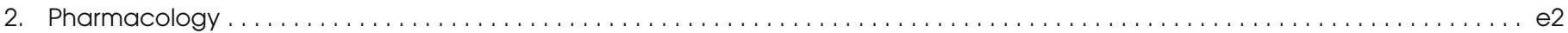

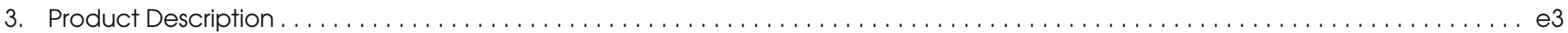

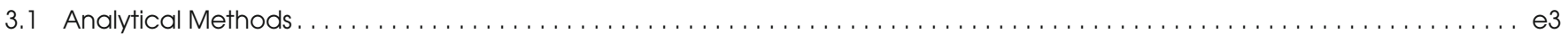

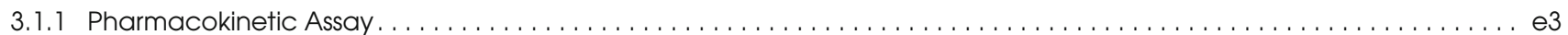

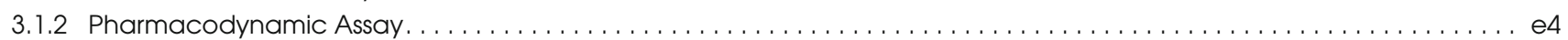

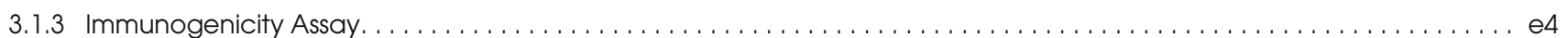

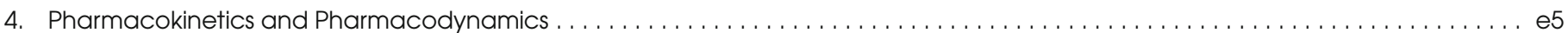

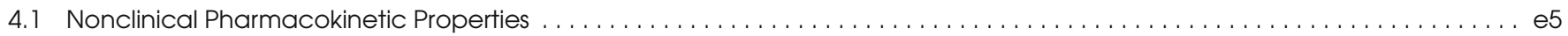

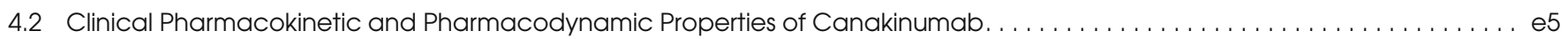

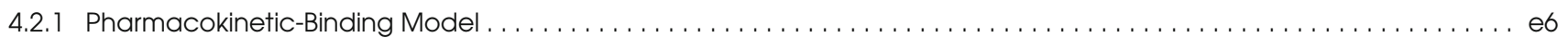

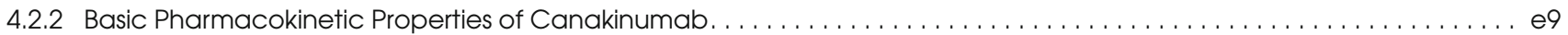

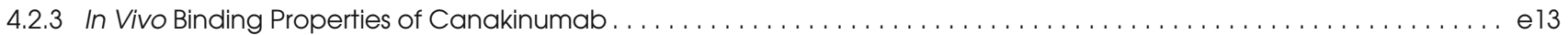

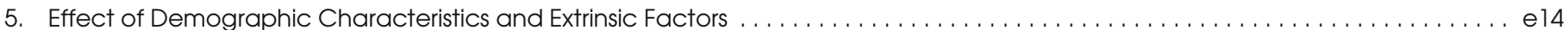

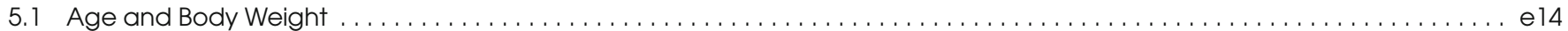

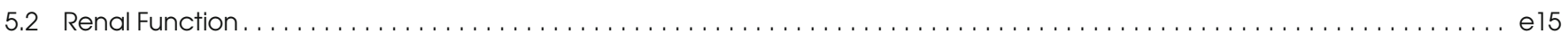

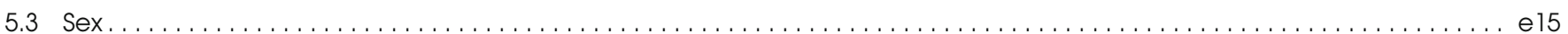

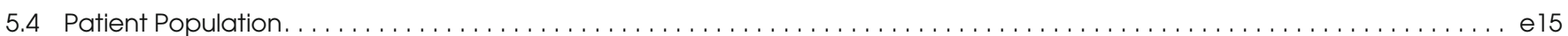

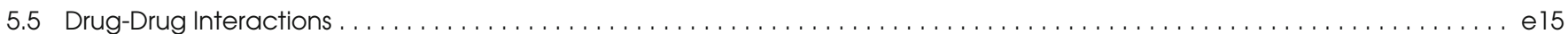

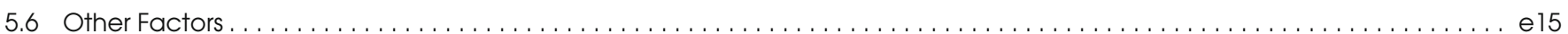

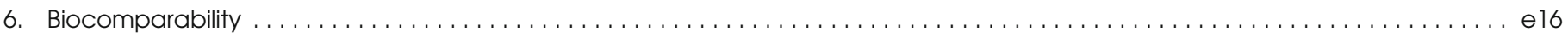

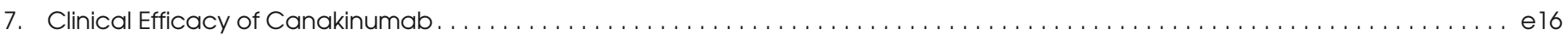

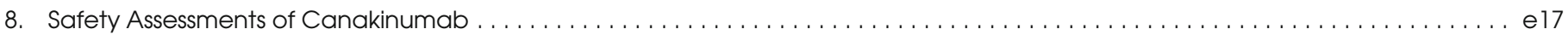

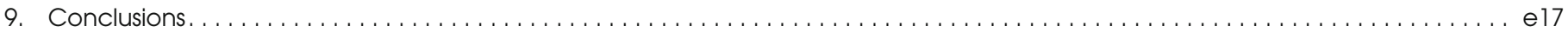

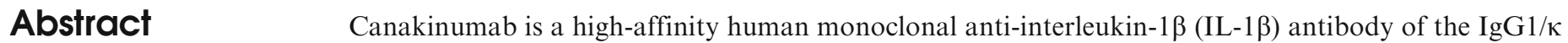
isotype designed to bind and neutralize the activity of human IL-1 $\beta$, a pro-inflammatory cytokine. Canakinumab is currently being investigated on the premise that it would exert anti-inflammatory effects on a broad spectrum of diseases, driven by IL-1 $\beta$. This paper focuses on the analysis of the pharmacokinetic and pharmacodynamic data from the canakinumab clinical development programme, describing results from 
the recently approved indication for the treatment of cryopyrin-associated periodic syndromes (CAPS) under the trade name ILARIS ${ }^{\circledR}$, as well as diseases such as rheumatoid arthritis, asthma and psoriasis.

Canakinumab displays pharmacokinetic properties typical of an $\mathrm{IgG} 1$ antibody. In a CAPS patient weighing $70 \mathrm{~kg}$, slow serum clearance $(0.174 \mathrm{~L} /$ day $)$ was observed with a low total volume of distribution at steady state $(6.0 \mathrm{~L})$, resulting in a long elimination half-life of 26 days. The subcutaneous absolute bioavailability was high $(70 \%)$. Canakinumab displays linear pharmacokinetics, with a dose-proportional increase in exposure and no evidence of accelerated clearance or time-dependent changes in pharmacokinetics following repeated administration was observed. The pharmacokinetics of canakinumab in various diseases (e.g. CAPS, rheumatoid arthritis, psoriasis or asthma) are comparable to those in healthy individuals. No sex- or age-related pharmacokinetic differences were observed after correction for body weight.

An increase in total IL-1 $\beta$ was observed in both healthy subjects and all patient populations following canakinumab dosing, reflecting the ability of canakinumab to bind circulating IL-1 $\beta$. The kinetics of total IL-1 $\beta$ along with the pharmacokinetics of canakinumab were characterized by a population-based pharmacokinetic-binding model, where the apparent in vivo dissociation constant, signifying binding affinity of canakinumab to circulating IL- $1 \beta$, was estimated at $1.07 \pm 0.173 \mathrm{nmol} / \mathrm{L}$ in CAPS patients.

During development of canakinumab a cell line change was introduced. Pharmacokinetic characterization was performed in both animals and humans to assure that this manufacturing change did not affect the pharmacokinetic/pharmacodynamic properties of canakinumab.

\section{Introduction}

Canakinumab is a high-affinity human anti-interleukin (IL)-1 $\beta$ monoclonal antibody of the $\mathrm{IgG} 1 / \kappa$ isotype, which functionally neutralizes the bioactivity of this pro-inflammatory cytokine. Its specificity is confined to human and marmoset IL-1 $\beta$, and does not cross-react with cynomolgus or rhesus monkey IL-1 $\beta$. IL- $1 \beta$ is produced mainly by mononuclear phagocytes in response to injury and infection and plays a dominant role in the pathobiology of autoinflammatory syndromes, such as cryopyrin-associated periodic syndromes (CAPS), ${ }^{[1-3]}$ systemic juvenile idiopathic arthritis, ${ }^{[4]}$ adult and juvenile rheumatoid arthritis, ${ }^{[5]}$ and gouty arthritis. ${ }^{[6]}$ IL- $1 \beta$ is also indicated to play a key role in other chronic inflammatory conditions such as asthma, ${ }^{[7]}$ chronic obstructive pulmonary disease, ${ }^{[8]}$ psoriasis $^{[9]}$ and type 2 diabetes mellitus. ${ }^{[10]}$

The clinical effectiveness of canakinumab was demonstrated in CAPS patients in a randomized phase III clinical trial. ${ }^{[1]}$ CAPS is a group of rare, inherited, autoinflammatory conditions caused by single point mutations in the NALP3/CIASI gene resulting in increased production of IL- $1 \beta{ }^{[2]}$ CAPS covers a spectrum of individual disorders that could be classified into the following subtypes: (i) familial cold autoinflammatory syndrome, also known as familial cold urticaria; (ii) Muckle-Wells syndrome; and (iii) neonatal onset multisystem inflammatory disease, also known as chronic, infantile, neurologic, cutaneous, articular (CINCA) syndrome. Canakinumab treatment was associated with a decrease of IL- $1 \beta$-induced downstream mediators including IL-1 $\beta$ itself, IL-1 $\beta$ pathway-related genes, acute phase proteins such as serum amyloid A (SAA) and $\mathrm{C}$-reactive protein (CRP), resulting in rapid remission of symptoms in most patients. Canakinumab is approved in more than 40 countries for the treatment of CAPS under the trade name ILARIS $^{\circledR}$.

This paper summarizes the clinical pharmacokinetic and pharmacodynamic data of canakinumab in healthy individuals as well as in several patient populations (rheumatoid arthritis [RA], psoriasis and asthma), with special emphasis on CAPS patients. The data for this paper are based on six clinical trials with canakinumab (pharmacokinetics/pharmacodynamics), as detailed in table I.

\section{Pharmacology}

IL-1 is an inflammatory cytokine produced by a variety of cell types, particularly mononuclear phagocytes, in response to injury, infection and cellular activation. The biological activity of IL- 1 is encoded by two distinct genes, $I L-1 \alpha$ and $I L-1 \beta$, with IL-1 $\beta$ being the main secreted form in vivo. The equilibrium dissociation constant for canakinumab binding to human IL-1 $\beta$, determined by surface plasmon resonance, is $60 \mathrm{pmol} / \mathrm{L}$ (unpublished data from the authors). Canakinumab inhibits the IL-6 production in human primary fibroblasts induced by human IL-1 $\beta$ with a concentration producing $50 \%$ inhibition $\left(\mathrm{IC}_{50}\right)$ of about $40 \mathrm{pmol} / \mathrm{L}$ (unpublished data from the authors).

In vivo, following administration, the binding of canakinumab to circulating IL- $1 \beta$ results in the formation of a canakinumabIL-1 $\beta$ complex. This complex, due to its larger molecular size, is expected to be eliminated at a much slower rate than the free 
Table I. Summary of canakinumab clinical study designs

\begin{tabular}{|c|c|c|}
\hline Study & Objective & Dosing scheme \\
\hline $\mathrm{CACZ885B2101}^{[12]}$ & $\begin{array}{l}\text { Safety, tolerability and pharmacokinetics in healthy } \\
\text { subjects and safety, tolerability and pharmacokinetics/ } \\
\text { pharmacodynamics in mild asthmatic patients }\end{array}$ & $\begin{array}{l}\text { Three dose levels: } 1,3 \text { and } 10 \mathrm{mg} / \mathrm{kg} \text {, administered as a 2-hour IV infusion } \\
\text { on day } 1 \text { and day } 15\end{array}$ \\
\hline $\begin{array}{l}\text { CACZ885A1101 } \\
(\text { NCT00421226) })^{[13]}\end{array}$ & $\begin{array}{l}\text { Safety, tolerability and pharmacokinetics/ } \\
\text { pharmacodynamics in Japanese healthy volunteers }\end{array}$ & $\begin{array}{l}\text { Cohorts 1-3: } 1 \mathrm{mg} / \mathrm{kg}, 3 \mathrm{mg} / \mathrm{kg} \text { and } 600 \mathrm{mg} \text { administered as a 2-hour IV infusion } \\
\text { Cohorts 4-5: } 150 \text { and } 300 \mathrm{mg} \text { administered SC } \\
\text { Cohort 6: } 600 \mathrm{mg} \text { IV infusion followed } 2 \text { hours later by a } 300 \mathrm{mg} \text { SC dose }\end{array}$ \\
\hline $\begin{array}{l}\text { CACZ885A2101 } \\
(\text { NCT00619905) })^{[14]}\end{array}$ & $\begin{array}{l}\text { Safety, tolerability and pharmacokinetics/ } \\
\text { pharmacodynamics in patients with active RA taking } \\
\text { methotrexate }\end{array}$ & $\begin{array}{l}\text { Four dose levels: } 0.3,1.0,3.0 \text { and } 10.0 \mathrm{mg} / \mathrm{kg} \text {, administered on day } 1 \text { and } \\
\text { day } 15 \text { as a 2-hour IV infusion }\end{array}$ \\
\hline $\begin{array}{l}\text { CAZC885A2202 } \\
\text { (EudraCT no. } \\
2005-004119-31)^{[15]}\end{array}$ & $\begin{array}{l}\text { Safety, tolerability, immunogenicity and pharmacokinetics/ } \\
\text { pharmacodynamics in psoriasis patients }\end{array}$ & $\begin{array}{l}\text { Three treatment groups: } 150 \mathrm{mg} \text { SC SD, } 150 \mathrm{mg} \text { SC MD once a week for } \\
4 \text { weeks, and placebo. Dosing on days } 1,8,15 \text { and } 22\end{array}$ \\
\hline $\begin{array}{l}\text { CACZ885A2102 } \\
(\text { NCT00487708) })^{[16]}\end{array}$ & $\begin{array}{l}\text { Clinical efficacy, safety and pharmacokinetics/ } \\
\text { pharmacodynamics in patients with NALP3 mutations } \\
\text { (CAPS patients) }\end{array}$ & $\begin{array}{l}\text { Stage 1: } 10 \mathrm{mg} / \mathrm{kg} \text { 2-hour IV infusion; additional } 1 \mathrm{mg} / \mathrm{kg} \text { IV infusion at } \\
\text { relapse } \\
\text { Stage 2: } 150 \mathrm{mg} \mathrm{SC} \mathrm{(or} 2 \mathrm{mg} / \mathrm{kg} \text { for paediatric subjects) upon each relapse }\end{array}$ \\
\hline $\begin{array}{l}\text { CACZ885D2304 } \\
(\text { NCT00465985) }\end{array}$ & $\begin{array}{l}\text { Efficacy, safety, tolerability and pharmacokinetics/ } \\
\text { pharmacodynamics in patients with Muckle-Wells } \\
\text { syndrome (CAPS patients) }\end{array}$ & $\begin{array}{l}\text { Three-part trial (only parts I and II were used for pharmacokinetic/ } \\
\text { pharmacodynamic analysis) } \\
\text { Part I: } 150 \mathrm{mg} \text { SC (or } 2 \mathrm{mg} / \mathrm{kg} \text { for paediatric subjects } \leq 40 \mathrm{~kg} \text { ) SD } \\
\text { Part II: patients were assigned to one of the following two treatment arms in } \\
\text { a ratio of } 1: 1,150 \mathrm{mg} \text { or } 2 \mathrm{mg} / \mathrm{kg} \text { (for paediatric subjects } \leq 40 \mathrm{~kg} \text { ) SC every } \\
8 \text { weeks or placebo for up to } 24 \text { weeks }\end{array}$ \\
\hline
\end{tabular}

CAPS = cryopyrin-associated periodic syndromes; IV=intravenous; $\mathbf{M D}=$ multiple dose; $\mathbf{R A}=$ rheumatoid arthritis; $\mathbf{S C}=$ subcutaneous; $\mathbf{S D}=$ single dose.

IL-1 $\beta$, thus resulting in the elevation of total (free plus bound) IL-1 $\beta$ levels. Total IL-1 $\beta$ concentrations can therefore be used as a surrogate pharmacodynamic marker of 'drug activity' (i.e. binding of IL-1 $\beta$ by the antibody), as it is easily detected following canakinumab administration. The ability of canakinumab to bind and capture circulating IL- $1 \beta$ has been validated in all clinical studies, in patients and healthy volunteers (figures 1 and 2). Vugmeyster et al. ${ }^{[17]}$ reported examples of anti-cytokine proteins that function as 'cytokine traps' by binding the free circulating cytokine. The free circulating cytokines, which would have otherwise been eliminated rapidly, are cleared slowly, resulting in increased total circulating drug-bound cytokine.

\section{Product Description}

Canakinumab is a human anti-IL-1 $\beta$ monoclonal $\operatorname{IgG} 1 / \kappa$ antibody, expressed in Sp2/0 mouse myeloma cells, which was derived from a genetically engineered mouse carrying the human immunoglobulin repertoire. The cell line for canakinumab production was switched from NS0 to Sp2/0 during canakinumab development. NS0 is a mouse myeloma line originally derived from a plasmacytoma of a female Balb/c mouse. ${ }^{[18]}$ $\mathrm{Sp} 2 / 0-\mathrm{Ag} 14$ was isolated as a re-clone of Sp2/HL-Ag, which was derived in several steps from Sp2/HLGK, a hybrid between a BALB/c spleen cell with anti-sheep red blood cell activity and myeloma cell line X63-Ag8, ${ }^{[19]}$ itself derived from a plasmacytoma of a female BALB/c mouse. Except for the phase III trial in CAPS patients, ${ }^{[11]}$ the drug material from the NS0 cell line was used in all the clinical trials presented in the current review.

The relative molecular mass of canakinumab based on the amino acid composition without post-translational glycosylation, but including $\mathrm{N}$-terminal pyroglutamate formation and the C-terminal lysine residues at the heavy chains, is $145.157 \mathrm{kDa}$.

The product is supplied as a sterile, lyophilized powder for solution for injection in glass vials that contain $150 \mathrm{mg}$ of canakinumab. Canakinumab can be administered as an intravenous infusion over 120 minutes or as a subcutaneous injection. The approved starting dose of canakinumab for CAPS patients with body weight $>40 \mathrm{~kg}$ is $150 \mathrm{mg}$, and with body weight $\geq 15 \mathrm{~kg}$ and $\leq 40 \mathrm{~kg}$ is $2 \mathrm{mg} / \mathrm{kg}$, administered every 8 weeks as a single dose via subcutaneous injection. ${ }^{[20,21]}$

\subsection{Analytical Methods}

\subsubsection{Pharmacokinetic Assay}

Canakinumab was analysed in human serum using a specific competitive ELISA method with a lower limit of quantification (LLQ) of $100 \mathrm{ng} / \mathrm{mL}$. This method was based on a purified 
anti-idiotype anti-canakinumab antibody coated on microtiterplates. Serum samples (calibration, quality control or unknown samples) and biotin-labelled canakinumab, when simultaneously incubated, compete for binding to the antiidiotype anti-canakinumab antibody. Non-bound material was removed by washing. Bound biotinylated-canakinumab was detected by incubating horseradish peroxidase-conjugated streptavidin followed by washing and incubation with O-phenylenediamine dihydrochloride as substrate with detection at $490 / 650 \mathrm{~nm}$. The intra- and inter-day precision and accuracy were observed to be below $\pm 20 \%$ ( $\pm 25 \%$ at LLQ). Canakinumab is stable in human serum at $-20^{\circ} \mathrm{C}$ for at least 12 months.

IL-1 $\beta$ at high concentration levels interferes with the binding of canakinumab present in the sample or biotinylated canakinumab used for the quantification to the ELISA plate, showing that the assay is only able to quantify free canakinu-
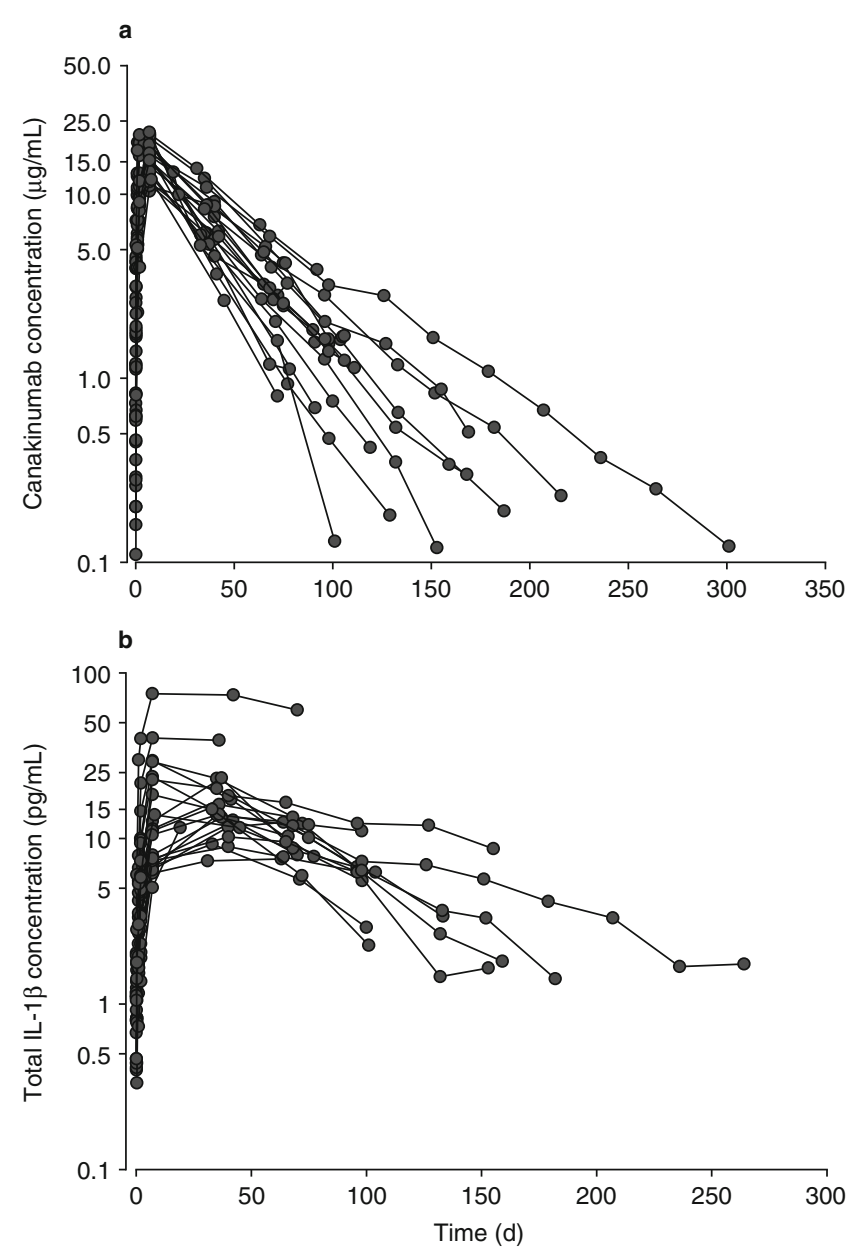

Fig. 1. Serum canakinumab (a) and total interleukin-1 $\beta$ (b) concentrationtime profiles in cryopyrin-associated periodic syndromes patients following subcutaneous administration of canakinumab $150 \mathrm{mg}$. The data are taken from study ACZ885A2102 (NCT00487708). ${ }^{[16]}$ IL = interleukin. mab. However, the highest observed concentration of total IL-1 $\beta$ during clinical studies (approximately $500 \mathrm{pg} / \mathrm{mL}$ or $0.03 \mathrm{nmol} / \mathrm{L}$ ) was observed with a corresponding canakinumab concentration of approximately $26 \mu \mathrm{g} / \mathrm{mL}(179 \mathrm{nmol} / \mathrm{L})$. In this most extreme case the percentage of canakinumab bound to its ligand target represents less than $0.02 \%$ of the systemic canakinumab concentration available for binding. The accuracy and precision of ELISA assays would therefore not allow differentiation between total canakinumab and free canakinumab.

\subsubsection{Pharmacodynamic Assay}

Total IL-1 $\beta$ (free + canakinumab-bound IL-1 $\beta$ ) was determined in human serum using a sandwich ELISA method based on a commercially available kit (Quantikine-HS, R\&D Systems, Minneapolis, MN, USA) with a lower limit of detection of $0.1 \mathrm{pg} / \mathrm{mL}$. Assay was performed as recommended by the manufacturer. Presence of canakinumab in the samples induces a partial inhibition of the IL-1 $\beta$ detection due to the binding of canakinumab to IL-1 $\beta$. The observed inhibition was constant for canakinumab concentrations from $30 \mathrm{ng} / \mathrm{mL}$ to $1.2 \mathrm{mg} / \mathrm{mL}$. Within this range, the average IL- $1 \beta$ recovery is $75 \%$ of the total IL- $1 \beta$ (measured in absence of canakinumab), with a coefficient of variation $(\mathrm{CV})$ of $5.9 \%$. On the basis of these results, a correction factor of $1.33(100 / 75)$ was applied to the determined IL- $1 \beta$ concentration when canakinumab was present in the sample at concentrations $>30 \mathrm{ng} / \mathrm{mL}$. The intraand inter-day precision and accuracy were below $\pm 20 \%$.

\subsubsection{Immunogenicity Assay}

A Biacore-based assay was developed and validated according to recommendations reported by Mire-Sluis et al. ${ }^{[22]}$ to detect presence of anti-canakinumab antibodies. The principle of the method is the interaction of anti-canakinumab antibodies with the canakinumab drug and was based on Surface Plasmon Resonance. The canakinumab drug was immobilized in a reversible manner to the Biacore sensor chip surface via protein $\mathrm{G}$, which was covalently bound to the sensor chip. Subsequently, samples were applied and anti-canakinumab antibodies were bound to the canakinumab drug. The resulting response was detected and given as response units. Acid regeneration after each cycle followed by a new injection of canakinumab ensured the integrity of the drug. A cycle was defined as drug injection, sample injection and regeneration. The sensitivity of this assay was determined to be $0.9 \mu \mathrm{g} / \mathrm{mL}$ based on a sheep polyclonal anti-canakinumab antibody. The drug tolerance was determined to be canakinumab $27 \mu \mathrm{g} / \mathrm{mL}$ based on the sheep polyclonal anti-canakinumab antibody. 

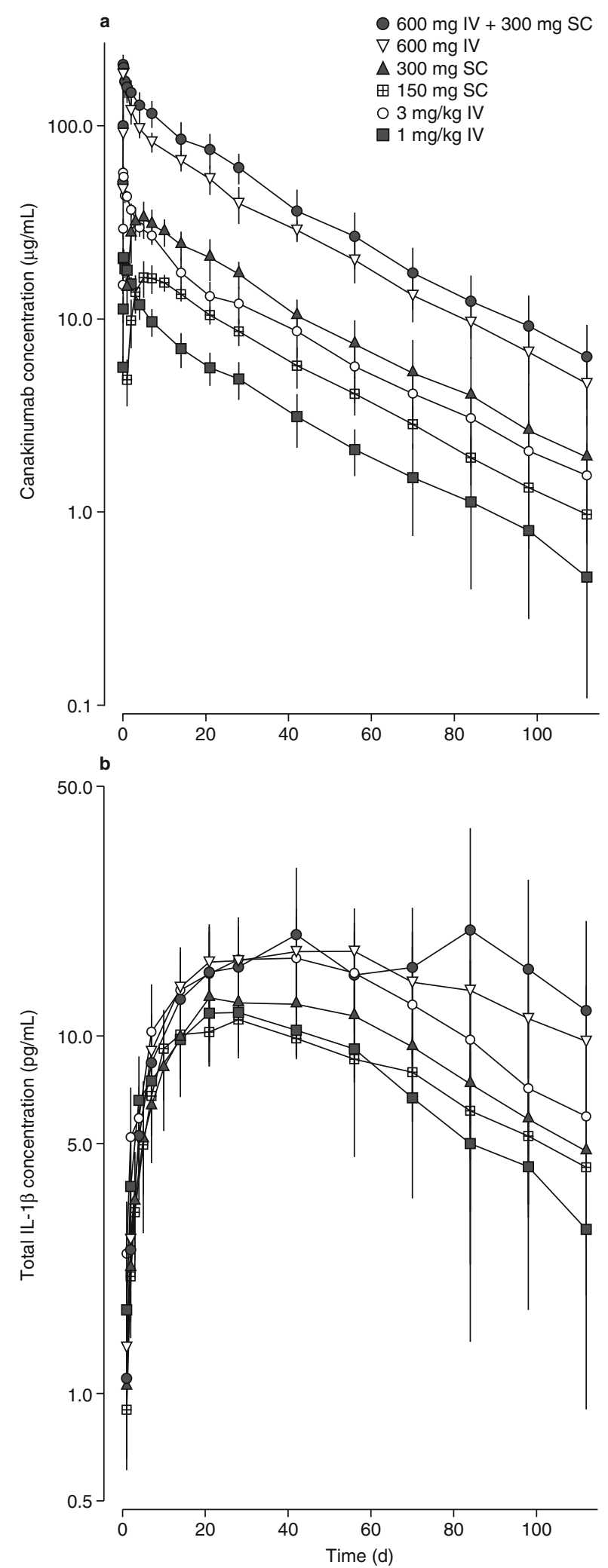

Fig. 2. Mean (and SD) serum canakinumab (a) and total interleukin-1 $\beta$ (b) concentration-time profiles in healthy Japanese volunteers after a single dose of canakinumab. The data are taken from study ACZ885A1101 (NCT00421226). ${ }^{[13]}$ IL = interleukin; IV = intravenous; $\mathbf{S C}=$ subcutaneous.

\section{Pharmacokinetics and Pharmacodynamics}

\section{1 Nonclinical Pharmacokinetic Properties}

The pharmacokinetics of canakinumab was studied in three animal species - rhesus monkeys, marmoset monkeys and mice - and is typical of an IgG-type antibody, with slow serum clearance and a small volume of distribution at steady state $\left(\mathrm{V}_{\mathrm{ss}}\right)$. Table II provides a comparison of intravenous pharmacokinetic parameters (calculated by non-compartmental analysis) in marmoset monkeys, rhesus monkeys, mice and four CAPS patients. The comparative pharmacokinetic profiles of canakinumab following intravenous administration in these species are presented in figure 3 . The weight-normalized serum clearance of canakinumab derived from the intravenous pharmacokinetic data reveals a faster clearance in marmoset monkeys than in other species $(0.005,0.004,0.003 \mathrm{~L} / \mathrm{day} / \mathrm{kg}$ in mice, rhesus monkeys and humans, respectively, vs $0.011 \mathrm{~L} / \mathrm{day} / \mathrm{kg}$ in marmosets). It is postulated that the more rapid clearance of human IgG1 antibodies in the marmoset monkey versus humans is due to reduced Ig recycling by the FcRn receptor in marmosets. ${ }^{[23]}$ The $\mathrm{V}_{\text {ss }}$ of canakinumab was $0.0025,0.26,0.021$ and $7.1 \mathrm{~L}$ in mice, rhesus monkeys, marmoset monkeys and humans, respectively. Accordingly, the half-lives of canakinumab in these species following intravenous administration of canakinumab were 17.7, 17.4, 4.33 and 31.2 days, respectively. The bioavailability of canakinumab following single subcutaneous administration in marmosets was estimated to be $60 \%$, similar to the bioavailability in humans $(60-70 \%)$.

\subsection{Clinical Pharmacokinetic and Pharmacodynamic Properties of Canakinumab}

The pharmacokinetics and pharmacodynamics (i.e. total IL-1 $\beta$ ) of canakinumab have been characterized in healthy volunteers as well as in patients with CAPS, RA, asthma and psoriasis. Canakinumab was administered in these studies by intravenous infusion and/or subcutaneous injections, at a range of doses under single- and multiple-dose regimens. The pharmacokinetics and pharmacodynamics were characterized in the various studies using extensive and/or sparse sampling. An overview of the study designs and treatment assignments in each study from which pharmacokinetic and pharmacodynamic data were analysed is provided in table $\mathrm{I}$.

For studies that implemented rich sampling, the serum pharmacokinetic parameters of canakinumab were determined using non-compartmental analysis (table III). Concentrations of canakinumab and total IL-1 $\beta$ data from these studies and 
Table II. Summary of non-compartmental pharmacokinetic parameters of canakinumab across species (mean \pm standard deviation)

\begin{tabular}{lllll}
\hline Parameters & Mouse $^{\mathrm{a}}$ & Rhesus monkey $^{\mathrm{b}}$ & Marmoset monkey $^{\mathrm{c}}$ & Human $^{\mathrm{d}}$ \\
\hline $\mathrm{CL}(\mathrm{L} /$ day $)$ & 0.00010 & $0.0118 \pm 0.0017$ & $0.00378 \pm 0.0010$ & $0.182 \pm 0.0528$ \\
$\mathrm{CL}(\mathrm{L} /$ day/kg) & 0.00494 & $0.00392 \pm 0.00056$ & $0.0108 \pm 0.00288$ & $0.00260 \pm 0.000754$ \\
$\mathrm{~V}_{\mathrm{ss}}(\mathrm{L})$ & 0.00247 & $0.262 \pm 0.0744$ & $0.0205 \pm 0.0044$ & $7.08 \pm 2.12$ \\
$\mathrm{t}_{1 / 2}$ (day) & 17.7 & $17.4 \pm 5.24$ & $4.33 \pm 0.548$ & $31.2 \pm 3.39$ \\
$\mathrm{~F}(\%)^{f}$ & $\mathrm{NA}$ & $\mathrm{NA}$ & 60 & 66.5 \\
\hline
\end{tabular}

a CD-1 mice were administered a single dose of IV canakinumab $10 \mathrm{mg} / \mathrm{kg}$; serum samples per timepoint were pooled (16 samples per timepoint) to one aliquot for the ELISA assay, with pharmacokinetic parameters determined from a single profile (Novartis preclinical data).

b Four rhesus monkeys were administered a single dose of IV canakinumab $2 \mathrm{mg} / \mathrm{kg}$ (Novartis preclinical data).

C Three marmosets were administered a single dose of IV canakinumab $5 \mathrm{mg} / \mathrm{kg}$ (Novartis preclinical data).

d Four CAPS patients were administered IV canakinumab $10 \mathrm{mg} / \mathrm{kg}$ in study NCT00487708. ${ }^{[16]}$

e Serum clearance normalized to a typical body weight of $20 \mathrm{~g}, 3 \mathrm{~kg}, 350 \mathrm{~g}$ and $70 \mathrm{~kg}$ for mouse, rhesus monkey, marmoset monkey and human, respectively.

f Subcutaneous bioavailability in marmosets was calculated based on Novartis preclinical data where marmosets were administered an SC dose of canakinumab $5 \mathrm{mg} / \mathrm{kg}$; SC bioavailability in humans was calculated from four CAPS patients in study NCT00487708 receiving $10 \mathrm{mg} / \mathrm{kg}$ IV and $150 \mathrm{mg}$ SC doses of canakinumab on separate occasions.

CAPS = cryopyrin-associated periodic syndromes; $\mathbf{C L}=$ serum clearance; $\mathbf{F}=$ absolute subcutaneous bioavailability; $\mathbf{I V}=$ intravenous; $\mathbf{N A}=$ not available; $\mathbf{S C}=$ subcutaneous; $\mathbf{t}_{1 / 2}=$ terminal elimination half-life; $\mathbf{V}_{\mathbf{s s}}=$ volume of distribution at steady state.

those with sparse sampling were also analysed using a nonlinear mixed-effects pharmacokinetic-binding modelling approach adapted from Lachmann et al. ${ }^{[16]}$ The pharmacokinetic-binding model integrated both canakinumab and IL-1 $\beta$ inputs and elimination, plus the binding affinity of canakinumab to IL-1 $1 \beta$. The model also included distribution of canakinumab and IL-1 $\beta$ between peripheral ('tissue interstitial') and central ('serum') compartments.

\subsubsection{Pharmacokinetic-Binding Model}

Population parameters in the pharmacokinetic-binding model were estimated using nonlinear mixed-effects modelling implemented in NONMEM ${ }^{\circledR}$ VI (level 1.2; Icon Development Solutions, Ellicott City, MD, USA), ${ }^{[24]}$ using the first-order estimation method. A description of the pharmacokineticbinding model is provided in this section followed by the presentation of the analysis results.

\section{The Structural Model}

A schematic depiction of the pharmacokinetic-binding model is shown in figure 4. The model contains two physical compartments, central and peripheral, with three components in each. The binding of drug (canakinumab) plus target (IL-1 $\beta$ ) to form a complex is assumed to take place in the same physical space; this was judged physiologically reasonable given both are hydrophilic proteins and thus constrained to be in the extracellular fluid. Differential equations have been written based on the schematic for the amount of canakinumab at the sub- cutaneous injection site (A), the total drug (canakinumab) in the serum or central compartment $\left(\mathrm{TD}_{\mathrm{C}}\right.$; measured analyte) and peripheral compartment $\left(\mathrm{TD}_{\mathrm{P}}\right)$, and the total ligand (IL-1 $\beta$ ) in the serum or central compartment $\left(\mathrm{TL}_{\mathrm{C}}\right.$; measured analyte) and peripheral compartment $\left(\mathrm{TL}_{\mathrm{P}}\right)$. Free (unbound) species are similarly represented by $\mathrm{FD}_{\mathrm{C}}, \mathrm{FD}_{\mathrm{P}}, \mathrm{FL}_{\mathrm{C}}$ and $\mathrm{FL}_{\mathrm{P}}$. The bound

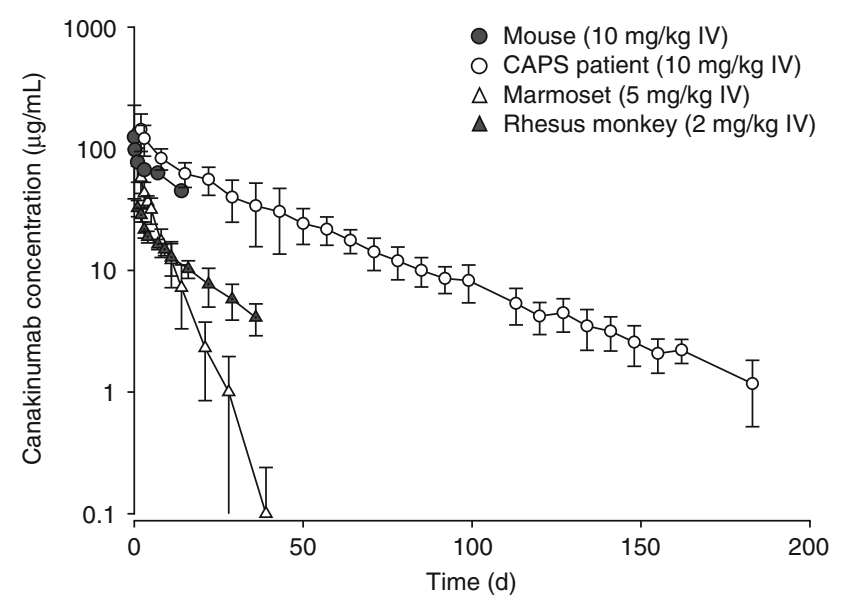

Fig. 3. Serum concentration-time profiles of canakinumab in adult cryopyrinassociated periodic syndrome patients, rhesus monkeys, marmoset monkeys (mean \pm standard deviation) and mice after a single intravenous administration of canakinumab. The data are taken from study CACZ885A2102 (NCT00487708) $^{[16]}$ for the cryopyrin-associated periodic syndrome pharmacokinetic profile, and from animal pharmacokinetic studies (Novartis preclinical data) for marmosets ( $5 \mathrm{mg} / \mathrm{kg}$ intravenous), CD-1 mice $(10 \mathrm{mg} / \mathrm{kg}$ intravenous) and rhesus monkeys ( $2 \mathrm{mg} / \mathrm{kg}$ intravenous). CAPS = cryopyrinassociated periodic syndromes; IV = intravenous. 
Table III. Non-compartmental pharmacokinetic parameters of canakinumab across studies and patient populations ${ }^{\mathrm{a}}$

\begin{tabular}{|c|c|c|c|c|c|c|c|}
\hline $\begin{array}{l}\text { Number of } \\
\text { subjects (type) }\end{array}$ & Dose and route & $\mathrm{C}_{\max }(\mu \mathrm{g} / \mathrm{mL})$ & $t_{\max }(d)^{b}$ & $t_{1 / 2}(d)$ & $\mathrm{V}_{\mathrm{z}}$ or $\mathrm{V}_{\mathrm{z}} / \mathrm{F}(\mathrm{L})$ & $\mathrm{V}_{\mathrm{ss}}$ & $\mathrm{CL}$ or $\mathrm{CL} / \mathrm{F}(\mathrm{L} /$ day $)$ \\
\hline \multicolumn{8}{|c|}{ Healthy subjects and patients with mild asthma (study CACZ885B2101) ${ }^{[12]}$} \\
\hline 6 (healthy) & $1 \mathrm{mg} / \mathrm{kg}$ IV (day 1,15$)$ & $36.8 \pm 5.78$ & & $30.9 \pm 1.50$ & $5.55 \pm 1.42$ & & $0.125 \pm 0.0344$ \\
\hline 6 (healthy) & $3 \mathrm{mg} / \mathrm{kg}$ IV (day 1,15$)$ & $111 \pm 15.3$ & & $31.2 \pm 6.44$ & $5.26 \pm 1.16$ & & $0.120 \pm 0.0343$ \\
\hline 5 (healthy) & $10 \mathrm{mg} / \mathrm{kg}$ IV (day 1,15$)$ & $336 \pm 20.2$ & & $26.4 \pm 5.70$ & $5.07 \pm 0.990$ & & $0.137 \pm 0.0351$ \\
\hline 20 (asthmatic) & 10 mg/kg IV (day 1,15$)$ & $395 \pm 79.7$ & & $25.7 \pm 3.24$ & $5.64 \pm 1.65$ & & $0.156 \pm 0.0643$ \\
\hline \multicolumn{8}{|c|}{ Japanese healthy subjects (study NCT00421226) ${ }^{[13]}$} \\
\hline 6 (healthy) & $1 \mathrm{mg} / \mathrm{kg}$ IV SD & $21 \pm 2.44$ & & $22.6 \pm 2.99$ & & $5.44 \pm 0.921$ & $0.174 \pm 0.0446$ \\
\hline 6 (healthy) & $3 \mathrm{mg} / \mathrm{kg}$ IV SD & $57.5 \pm 5.85$ & & $27.4 \pm 5.41$ & & $5.65 \pm 0.959$ & $0.160 \pm 0.0292$ \\
\hline 6 (healthy) & $600 \mathrm{mg}$ IV SD & $191 \pm 21.2$ & & $27.2 \pm 6.61$ & & $5.77 \pm 0.533$ & $0.168 \pm 0.0239$ \\
\hline 6 (healthy) & $150 \mathrm{mg}$ SC SD & $16.9 \pm 2.62$ & $5.00(5.00-9.94)$ & $26.3 \pm 2.02$ & $8.70 \pm 1.34$ & & $0.229 \pm 0.0319$ \\
\hline 6 (healthy) & $300 \mathrm{mg}$ SC SD & $34.1 \pm 6.09$ & $5.00(2.00-5.00)$ & $26.9 \pm 8.23$ & $8.92 \pm 1.64$ & & $0.238 \pm 0.0421$ \\
\hline 6 (healthy) & $600 \mathrm{mg} \mathrm{IV}+300 \mathrm{mg} \mathrm{SC}$ & $209 \pm 24.9$ & & $25.2 \pm 4.00$ & & & \\
\hline \multicolumn{8}{|c|}{ Patients with active rheumatoid arthritis (study CACZ885A2101 [NCT00619905]) ${ }^{[14]}$} \\
\hline 5 (RA) & $0.3 \mathrm{mg} / \mathrm{kg} \mathrm{IV} \mathrm{(day} 1,15)$ & $8.80 \pm 1.50$ & & $19.6 \pm 2.30$ & $7.89 \pm 1.52$ & & $0.283 \pm 0.0640$ \\
\hline $6(\mathrm{RA})$ & $1 \mathrm{mg} / \mathrm{kg}$ IV (day 1,15$)$ & $32.2 \pm 8.50$ & & $23.7 \pm 8.80$ & $6.35 \pm 0.870$ & & $0.203 \pm 0.0680$ \\
\hline $6(\mathrm{RA})$ & $3 \mathrm{mg} / \mathrm{kg}$ IV (day 1,15$)$ & $81.9 \pm 16.2$ & & $21.7 \pm 3.0$ & $6.16 \pm 1.30$ & & $0.199 \pm 0.0430$ \\
\hline $20(\mathrm{RA})$ & 10 mg/kg IV (day 1,15$)$ & $329 \pm 62.1$ & & $21.2 \pm 5.1$ & $5.87 \pm 1.57$ & & $0.200 \pm 0.0660$ \\
\hline \multicolumn{8}{|c|}{ Patients with psoriasis (study CAZC885A2202 [EudraCT no. 2005-004119-31]) ${ }^{[15]}$} \\
\hline 10 (psoriasis) & $150 \mathrm{mg} \mathrm{SC} \mathrm{SD}$ & $11.9 \pm 4.89$ & $5.00(2.00-14.0)$ & $26.2 \pm 5.16$ & $15.0 \pm 9.96$ & & $0.430 \pm 0.341$ \\
\hline \multicolumn{8}{|c|}{ CAPS patients with NALP3 mutations (study CACZ885A2102 [NCT00487708]) ${ }^{[16]}$} \\
\hline 4 (adult CAPS) & $10 \mathrm{mg} / \mathrm{kg}$ IV SD & $149 \pm 45.4$ & & $31.2 \pm 3.39$ & $8.19 \pm 2.42$ & $7.08 \pm 2.12$ & $0.182 \pm 0.0528$ \\
\hline 25 (adult CAPS) & $150 \mathrm{mg}$ SC SD & $15.9 \pm 3.52$ & $6.98(1.92-14.0)$ & $26.1 \pm 7.31$ & $8.33 \pm 2.62$ & & $0.228 \pm 0.0597$ \\
\hline 2 (paediatric CAPS) & $150 \mathrm{mg}$ SC SD & 13.4 & $4.61(2.16-7.05)$ & 22.9 & 7.67 & & 0.232 \\
\hline 3 (paediatric CAPS) & $2 \mathrm{mg} / \mathrm{kg} \mathrm{SC} \mathrm{SD}$ & $11.2 \pm 3.14$ & $2.00(2.00-6.96)$ & $24.7^{c}$ & $3.39^{c}$ & & $0.0966^{c}$ \\
\hline
\end{tabular}

a All values given are for mean \pm standard deviation, unless otherwise specified.

b Median (range) for single SC dose.

c Data are presented for two subjects as the elimination phase could not be characterized for the third patient.

CAPS = cryopyrin-associated periodic syndromes; $\mathbf{C L}=$ total serum clearance estimated from IV data; $\mathbf{C L} / \mathbf{F}=$ apparent total serum clearance estimated from SC data; $\mathbf{C}_{\max }=$ maximum (peak) serum concentration; $\mathbf{F}=$ absolute $\mathrm{SC}$ bioavailability; $\mathbf{I V}=2$-hour intravenous infusion; $\mathbf{R A}=$ rheumatoid arthritis; $\mathbf{S C}=$ subcutaneous; $\mathbf{S D}=$ single dose; $\mathbf{t}_{1 / 2}=$ elimination half-life; $\mathbf{t}_{\mathbf{m a x}}=$ time of peak serum concentration (from $\mathbf{S C}$ administration); $\mathbf{V}_{\mathbf{s s}}=$ volume of distribution at steady state; $\mathbf{V}_{\mathbf{z}}=$ volume of distribution (based on the terminal phase estimated from IV data); $\mathbf{V}_{\mathbf{z}} / \mathbf{F}=$ apparent volume of distribution (based on the terminal phase estimated from SC data).

species (the canakinumab-IL-1 $\beta$ complex) is represented by ' $\mathrm{X}$ ', where $X_{C}$ and $X_{P}$ are the complexes in the central and peripheral compartments, respectively. All species in the equations are in molar units (i.e. amounts); amounts were then converted to concentrations by dividing by the appropriate compartment volume.

The equations are as follows:

Canakinumab absorption from the subcutaneous injection site (equation 1):

$$
\mathrm{dA} / \mathrm{dt}=-\mathrm{k}_{\mathrm{a}} \bullet \mathrm{A}
$$

where $\mathrm{k}_{\mathrm{a}}$ is the first-order absorption rate constant. Canakinumab was also administered as a 2-hour infusion, allowing for the estimation of the subcutaneous bioavailability.

The total drug (canakinumab) concentration in the serum or central compartment, $\mathrm{TD}_{\mathrm{C}}$ (equation 2):

$$
\begin{aligned}
\mathrm{dTD}_{\mathrm{C}} / \mathrm{dt}= & \mathrm{k}_{\mathrm{a}} \bullet \mathrm{A}-\mathrm{X}_{\mathrm{C}} \bullet \mathrm{CL} \mathrm{L}_{\mathrm{X}} / \mathrm{V}_{\mathrm{C}}-\left(\mathrm{TD}_{\mathrm{C}}-\mathrm{X}_{\mathrm{C}}\right) \\
& \bullet \mathrm{CL}_{\mathrm{D}} / \mathrm{V}_{\mathrm{C}}+\left(\mathrm{TD}_{\mathrm{P}} / \mathrm{V}_{\mathrm{P}}-\mathrm{TD}_{\mathrm{C}} / \mathrm{V}_{\mathrm{C}}\right) \bullet \mathrm{PS}_{\mathrm{D}} \quad \text { (Eq. 2) }
\end{aligned}
$$

where $C L_{X}$ and $C L_{D}$ are the clearances of the canakinumabIL- $1 \beta$ complex and free canakinumab, respectively, which were 
assumed to be the same; $V_{C}$ and $V_{P}$ are the volumes of distribution of the central (serum) and peripheral compartments, assumed to be the same for canakinumab, IL-1 $\beta$ and the complex; and $\mathrm{PS}_{\mathrm{D}}$ is the intercompartmental permeability-surface area coefficient (distributional clearance) between central and peripheral compartments for free canakinumab and the complex.

The total drug (canakinumab) concentration in the peripheral compartment, $\mathrm{TD}_{\mathrm{P}}$ (equation 3 ):

$$
\mathrm{dTD}_{\mathrm{P}} / \mathrm{dt}=\left(\mathrm{TD}_{\mathrm{C}} / \mathrm{V}_{\mathrm{C}}-\mathrm{TD}_{\mathrm{P}} / \mathrm{V}_{\mathrm{P}}\right) \bullet \mathrm{PS}_{\mathrm{D}}
$$

The total IL-1 $\beta$ concentration in the serum or central compartment, $\mathrm{TL}_{\mathrm{C}}$ (equation 4 ):

$\mathrm{dTL}_{\mathrm{C}} / \mathrm{dt}=-\mathrm{X}_{\mathrm{C}} \bullet \mathrm{CL}_{\mathrm{X}} / \mathrm{V}_{\mathrm{C}}-\mathrm{FL}_{\mathrm{C}} \bullet \mathrm{CL}_{\mathrm{L}} / \mathrm{V}_{\mathrm{C}}+\left(\mathrm{FL}_{\mathrm{P}} / \mathrm{V}_{\mathrm{P}}-\mathrm{FL}_{\mathrm{C}} / \mathrm{V}_{\mathrm{C}}\right)$

$$
\text { - } \mathrm{PS}_{\mathrm{L}}+\left(\mathrm{X}_{\mathrm{P}} / \mathrm{V}_{\mathrm{P}}-\mathrm{X}_{\mathrm{C}} / \mathrm{V}_{\mathrm{C}}\right) \bullet \mathrm{PS}_{\mathrm{D}}
$$

where $C L_{L}$ is the clearance of free IL-1 $\beta$ and $\mathrm{PS}_{\mathrm{L}}$ is the exchange coefficient for the free IL-1 $\beta$ between the central and peripheral compartments.

The total IL-1 $\beta$ concentration in the peripheral compartment, $\mathrm{TL}_{\mathrm{P}}$ (equation 5):

$$
\begin{aligned}
\mathrm{dTL}_{\mathrm{P}} / \mathrm{dt}= & \mathrm{R}_{\mathrm{LI}} / 17000+\left(\mathrm{FL}_{\mathrm{C}} / \mathrm{V}_{\mathrm{C}}-\mathrm{FL}_{\mathrm{P}} / \mathrm{V}_{\mathrm{P}}\right) \\
& \bullet \mathrm{PS}_{\mathrm{L}}+\left(\mathrm{X}_{\mathrm{C}} / \mathrm{V}_{\mathrm{C}}-\mathrm{X}_{\mathrm{P}} / \mathrm{V}_{\mathrm{P}}\right) \bullet \mathrm{PS}_{\mathrm{D}}
\end{aligned}
$$

where $T L_{P}$ is assumed to gain mass of IL-1 $\beta$ from the endogenous production rate of IL-1 $\beta$, denoted as $R_{L I}$, converted from $\mathrm{ng} / \mathrm{day}$ into nmol/day by the molecular mass of $17000 \mathrm{ng} / \mathrm{nmol}$.

The amount of canakinumab-IL-1 $\beta$ complex was determined by the law of mass action, assuming rapid achievement of equilibrium binding (quasi-steady-state assumption) [equation 6]:

$$
\mathrm{K}_{\mathrm{D}}=[\mathrm{FD}] \bullet[\mathrm{FL}] /[\mathrm{X}]
$$

where $K_{D}$ is the equilibrium dissociation constant for binding of canakinumab to IL- $1 \beta$. Rearrangement of the previous equation gives the amount of the canakinumab-IL-1 $\beta$ complex in the central compartment as a quadratic solution to the binding equation (equation 7): $[16,25]$

$\mathrm{X}_{\mathrm{C}}=$

$\frac{\left[\left(\mathrm{K}_{\mathrm{D}} \bullet \mathrm{V}_{\mathrm{C}}+\mathrm{TD}_{\mathrm{C}}+\mathrm{TL}_{\mathrm{C}}\right)-\sqrt{\left(\mathrm{K}_{\mathrm{D}} \bullet \mathrm{V}_{\mathrm{C}}+\mathrm{TD}_{\mathrm{C}}+\mathrm{TL}_{\mathrm{C}}\right)^{2}-4 \bullet \mathrm{TD}_{\mathrm{C}} \bullet \mathrm{TL}_{\mathrm{C}}}\right]}{2}$

(Eq. 7)

This equation was replicated for the analogous equilibrium of drug, ligand and complex in the peripheral compartment (subscript $\mathrm{P}$ instead of $\mathrm{C}$ ). The quantities of canakinumab-IL$1 \beta$ complex, $X_{C}$ and $X_{P}$, were thus available as a function of total drug, total ligand and the $\mathrm{K}_{\mathrm{D}}$ for use in equations 2,4 and 5. Simultaneous fitting of canakinumab and total IL-1 $\beta$ data therefore enabled the estimation of pharmacokinetic parameters as well as the drug-ligand dissociation constant, $\mathrm{K}_{\mathrm{D}}$, and the rates of production and elimination of IL- $1 \beta$.

The Stochastic Model

The model was run with logarithmically transformed input concentration data. The residual error was therefore specified with an additive model and the output equations were logarithmically transformed. The final output of each measured analyte was given by equation 8 :

$$
\mathrm{Y}_{\mathrm{n}}=\log \left(\operatorname{IPRE}_{\mathrm{n}}\right)+\varepsilon_{\mathrm{n}}
$$

where IPRE $E_{n}$ was equal to the total amount of drug, $\mathrm{TD}_{\mathrm{C}}$, or ligand, $\mathrm{TL}_{\mathrm{C}}$, divided by the central compartment volume, $\mathrm{V}_{\mathrm{C}}$, and $\mathrm{n}$ the compartment number; and $\varepsilon_{\mathrm{n}}$ corresponded to the within-subject residual error variance for the respective analyte.

All patient-level parameters $\left(\theta_{\mathrm{P}, \mathrm{i}}\right)$ in the base model had a typical value for the population, $\theta_{\mathrm{P}}$, with a log-normally distributed, multiplicative patient-level effect, $\exp \left(\eta_{\mathrm{P}}\right)$ [equation 9]:

$$
\theta_{\mathrm{P}, \mathrm{i}}=\theta_{\mathrm{P}} \bullet \exp \left(\eta_{\mathrm{P}, \mathrm{i}}\right)
$$

In addition, the absolute bioavailability of the drug from the subcutaneous injection site was coded using a logit transformation in order to constrain it to be between 0 and 1 .

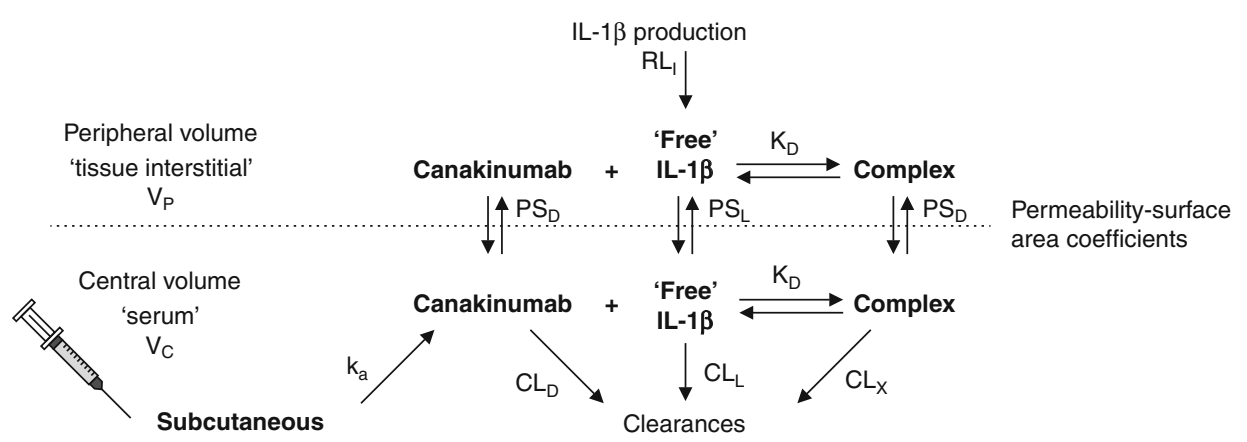

Fig. 4. Binding and kinetic model for canakinumab and interleukin-1 $\beta . C_{D}=$ clearance for drug; $C_{L}=c l e a r a n c e$ for ligand; $C L_{\mathbf{x}}=c l e a r a n c e$ for $c o m p l e x ;$ $\mathbf{I L}=$ interleukin; $\mathbf{k}_{\mathbf{a}}=$ absorption rate; $\mathbf{K}_{\mathbf{D}}=$ binding dissociation constant between drug and ligand; $\mathbf{P} \mathbf{S}_{\mathbf{D}}=$ intercompartmental permeability-surface area coefficient for drug; $\mathbf{P S}_{\mathbf{L}}=$ intercompartmental permeability-surface area coefficient for ligand; $\mathbf{R} \mathbf{L}_{\mathbf{I}}=$ production rate of ligand; $\mathbf{V}_{\mathbf{C}}=$ central volume; $\mathbf{V}_{\mathbf{P}}=$ peripheral volume. 
Covariates to explain inter-subject variability, such as body weight, age, sex, ethnicity, laboratory values (e.g. albumin levels), study population (CAPS patients, non-Japanese or Japanese healthy volunteers, RA, asthma or psoriasis patients) and cell line change, were evaluated in the model to assess any differences among the subgroups that might affect canakinumab pharmacokinetics or its binding affinity to IL-1 $\beta$. Covariate relationships and model components (such as random effects on parameters) were initially assessed based on graphical exploration of interindividual variance $\left(\eta_{\mathrm{P}, \mathrm{i}}\right)$ versus covariates, pharmacological or physiological plausibility as well as changes in the objective function. The covariates suggested by the graphical analysis were tested for inclusion in the model. In all cases, the relationship between parameters and continuous subject covariates was modelled with a centred power model. The influence of categorical subject covariates (e.g. patient type) was modelled as a proportional increase or decrease in the parameter value. Each potential covariate-parameter pair was formally tested for insertion into the model with a stepwise forward inclusion algorithm; all models were tested in parallel runs, after which the model with the largest drop in the objective function (at least 3.84 for a single parameter for $p<0.05$ significance) was then carried forward. If more than one covariate-parameter pair was added at the same time, the significance level was determined from a chi-squared $\left(\chi^{2}\right)$ statistical table for $\mathrm{p} \leq 0.05$ and the appropriate number of degrees of freedom.

\section{Pharmacokinetic-Binding Modelling Results}

The pharmacokinetic-binding model was applied to the pharmacokinetics and total IL- $1 \beta$ concentration data from the six clinical studies in table $\mathrm{I}(\mathrm{n}=233$ subjects). This model successfully fitted the canakinumab and total IL-1 $\beta$ concentration-time data (figure 5), allowing estimation of canakinumab pharmacokinetics and the dynamics of its binding to IL-1 $\beta$ in CAPS patients, other patient populations and healthy volunteers. The successful convergence and fit of the model indicated that the assumptions of pseudo-equilibrium, shared volumes of distribution and complex clearance equivalent to drug clearance were reasonable. Plots of the weighted residuals versus time from all six studies are individually presented and were well centred with relatively few outliers and little tendency to drift over time (figure 6).

The final model parameters are summarized in table IV. The parameters for a typical $70 \mathrm{~kg}$ CAPS patient with the median values of serum albumin of $43 \mathrm{~g} / \mathrm{L}$ and age 34 years were estimated as follows: $\mathrm{CL}_{\mathrm{D}} 0.174 \pm 0.0124 \mathrm{~L} /$ day; $\mathrm{V}_{\mathrm{C}} 3.30 \pm 0.135$; and $V_{P} 2.71 \pm 0.151 \mathrm{~L}$. Subcutaneous bioavailability ranged from $63 \%$ to $70 \%$ for the two cell lines. Canakinumab binding to IL-1 $\beta$ was reflected in the $\mathrm{K}_{\mathrm{D}}$ value of $1.1 \pm 0.2 \mathrm{nmol} / \mathrm{L}$ in the CAPS population. $\mathrm{CL}_{\mathrm{L}}$ was $14.2 \pm 2.55 \mathrm{~L}$ /day and $\mathrm{RL}_{\mathrm{I}}$ was $9.57 \pm 1.34 \mathrm{ng} / \mathrm{day}$. Interindividual variability was moderate for clearance and volume (24-29\% CV), and greater for the absorption rate $(64 \% \mathrm{CV})$ and the IL- $1 \beta$ binding and turnover (input-output) parameters (51-63\% CV). Canakinumab clearance and IL-1 $\beta$ production were well estimated with little shrinkage to the mean ( $4.6 \%$ and $10 \%$, respectively), reflecting good sampling design for these parameters. The less easy to estimate parameters were IL- $1 \beta$ clearance and the permeabilitysurface area coefficient, each of which exhibited moderate shrinkage (36\% and $45 \%$ for $\mathrm{PS}_{\mathrm{D}}$ and $\mathrm{PS}_{\mathrm{L}}$, respectively, and $27 \%$ for $\mathrm{CL}_{\mathrm{L}}$ ). Residual error shrinkage was low (7.6\% and $\left.10 \%\right)$, indicating that the two-compartment model was a good approximation of canakinumab and IL-1 $\beta$ disposition.

Covariates for the pharmacokinetic parameters were body weight, population type, and serum albumin levels on $\mathrm{CL}_{\mathrm{D}}$, body weight on $\mathrm{V}_{\mathrm{C}}$ and $\mathrm{V}_{\mathrm{P}}$, and age on the subcutaneous $\mathrm{k}_{\mathrm{a}}$. Covariates for the IL-1 $\beta$-related parameters were population type on IL-1 $\beta \mathrm{R}_{\mathrm{LI}}$ and $\mathrm{K}_{\mathrm{D}}$, and population type on IL- $1 \beta \mathrm{CL}_{\mathrm{L}}$. The relationship between parameters and subject covariates are provided in table IV and discussed in section 4.2.2 and section 5.

\subsubsection{Basic Pharmacokinetic Properties of Canakinumab}

\section{Absorption}

As shown in figure 1, following a single (initial) subcutaneous canakinumab $150 \mathrm{mg}$ administration in CAPS patients, canakinumab was slowly absorbed from the injection site reaching a maximum serum concentration $\left(\mathrm{C}_{\max }\right)$ of $15.9 \pm$ $3.52 \mu \mathrm{g} / \mathrm{mL}$ in approximately 7 days. Accordingly, the $\mathrm{k}_{\mathrm{a}}$ value estimated by the pharmacokinetic-binding value was low $\left(0.3 \mathrm{day}^{-1}\right)$. The absolute bioavailability of canakinumab derived from the NS0 cell line was estimated to be $63 \pm 5 \%$, while that from the Sp2/0 cell line was $70 \pm 8 \%$ (table IV). The incomplete bioavailability of canakinumab injected subcutaneously is likely due to proteolytic degradation within the reticuloendothelial system following uptake from the tissue interstitial rather than the blood side as the drug transits the lymphatics to the thoracic duct. The $63-70 \%$ subcutaneous bioavailability of canakinumab is in line with the bioavailability estimates of other $\operatorname{IgG}$ type monoclonal antibodies. ${ }^{[26]}$

\section{Distribution}

The apparent volume of distribution during the terminal phase computed by noncompartmental analysis following subcutaneous administration of canakinumab in adult CAPS patients was low, averaging $8.33 \pm 2.62 \mathrm{~L}$, slightly greater than 

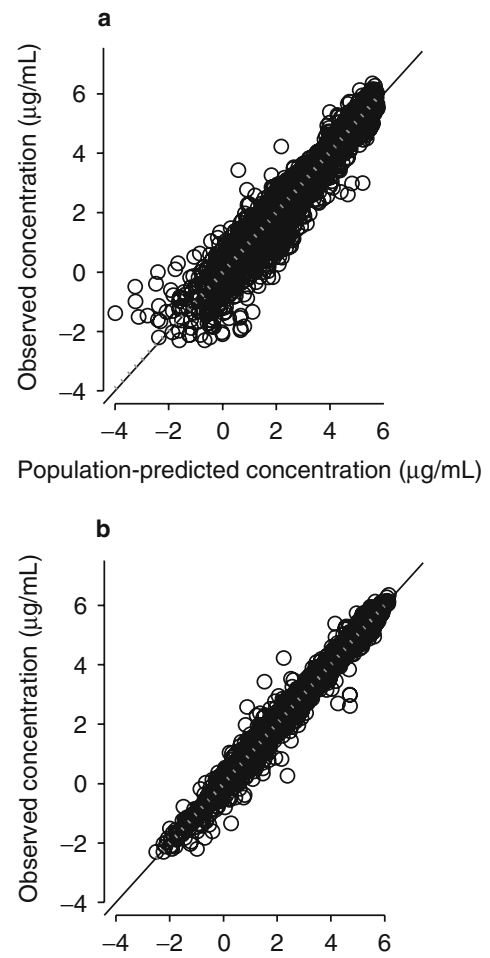

Individual-predicted concentration $(\mu \mathrm{g} / \mathrm{mL})$

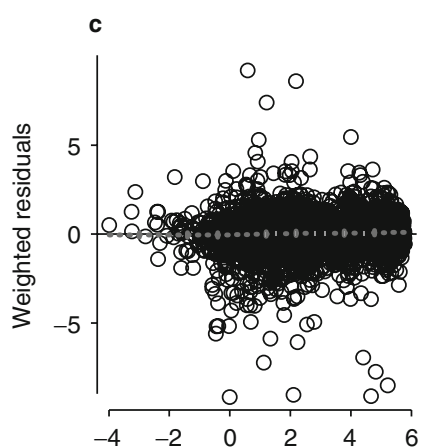

Population-predicted concentration $(\mu \mathrm{g} / \mathrm{mL})$
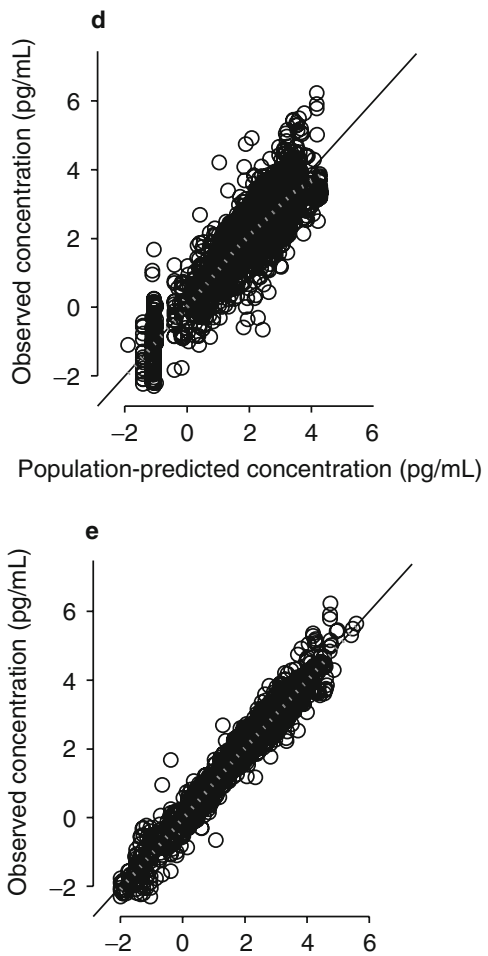

Individual-predicted concentration $(\mathrm{pg} / \mathrm{mL})$

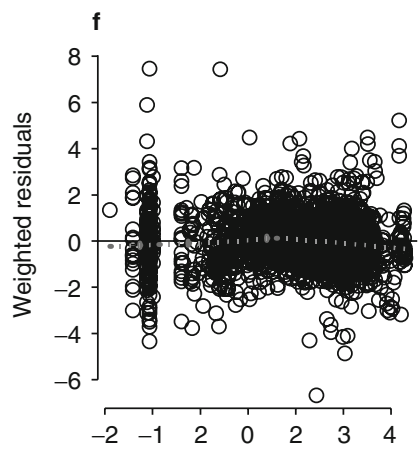

Population-predicted concentration $(\mathrm{pg} / \mathrm{mL}$ )

Fig 5. Diagnostic plots from the population-based pharmacokinetic-binding model for (a-c) canakinumab and (d-f) interleukin-1 $\beta$ : observed vs individual- and population-predicted concentrations and NONMEM ${ }^{\circledR}$ weighted residuals vs population-predicted concentrations. The line through each plot is a local regression.

the serum volume and typical for the distribution of large macromolecules (table III). Based on the pharmacokineticbinding model, the total $\mathrm{V}_{\mathrm{ss}}$ in a typical CAPS patient weighing $70 \mathrm{~kg}$ was estimated to be $6.0 \mathrm{~L}$. With a molecular weight of approximately $150 \mathrm{kDa}$, the extra-vascular distribution of canakinumab is expected to be very small.

\section{Elimination}

As canakinumab is a human $\operatorname{IgG}$ with a large molecular size $(\sim 150 \mathrm{kDa})$, little intact immunoglobulin can be filtered by the kidney and therefore not much renal excretion is expected. Secretion into the bile is not a significant contributor to the elimination of $\mathrm{IgG}$ antibodies. The majority of $\mathrm{IgG}$ elimination occurs via intracellular catabolism, following fluid-phase or receptor mediated endocytosis. ${ }^{[26]}$

In line with the pharmacokinetic properties of a typical IgG antibody, based on non-compartmental analysis, the apparent serum clearance after subcutaneous administration (CL/F) averaged $0.228 \mathrm{~L} /$ day in adult CAPS patients, resulting in a long elimination half-life $\left(t_{1 / 2}\right)$ averaging 26.1 days following single subcutaneous administration of canakinumab (table III). The serum clearance of canakinumab estimated by the pharmacokinetic-binding model was $0.174 \mathrm{~L} /$ day in a typical CAPS patient weighing $70 \mathrm{~kg}$; when this value was adjusted for a 
bioavailability of $70 \%, \mathrm{CL} / \mathrm{F}$ of $0.249 \mathrm{~L} /$ day agreed closely with the non-compartmental value.

\section{Dose Proportionality}

Canakinumab exhibits dose-proportional pharmacokinetics, both when given as an intravenous infusion $(0.3-10 \mathrm{mg} / \mathrm{kg})$ and when administered as a single subcutaneous injection (150-300 mg). There were three pharmacokinetic studies (healthy volunteers and RA patients; table III) in which at least three dose strengths of canakinumab were tested. In figure 7, dosenormalized exposure (area under the serum concentration-time curve [AUC]) values remain fairly constant across the intravenous dose range of $0.3-10 \mathrm{mg} / \mathrm{kg}$ in RA patients, indicat- ing dose-proportionality. ${ }^{[14]}$ Dose independence of canakinumab clearance was also demonstrated by plotting the individual estimates of clearance from the population pharmacokineticbinding model against the administered dose (figure 8). The linear regression slope of this relationship is approximately zero, indicating that clearance is dose-independent.

Even though the formation of canakinumab-IL-1 $\beta$ complexes had been demonstrated, there was no evidence of targetmediated drug disposition. Unlike target-mediated elimination, where clearance decreases as a function of dose, no dose- or concentration-dependent changes in elimination or exposure were observed, and the $\mathrm{V}_{\mathrm{ss}}$ was constant across the dose ranges. This is consistent with the hypothesis that antibodies that are
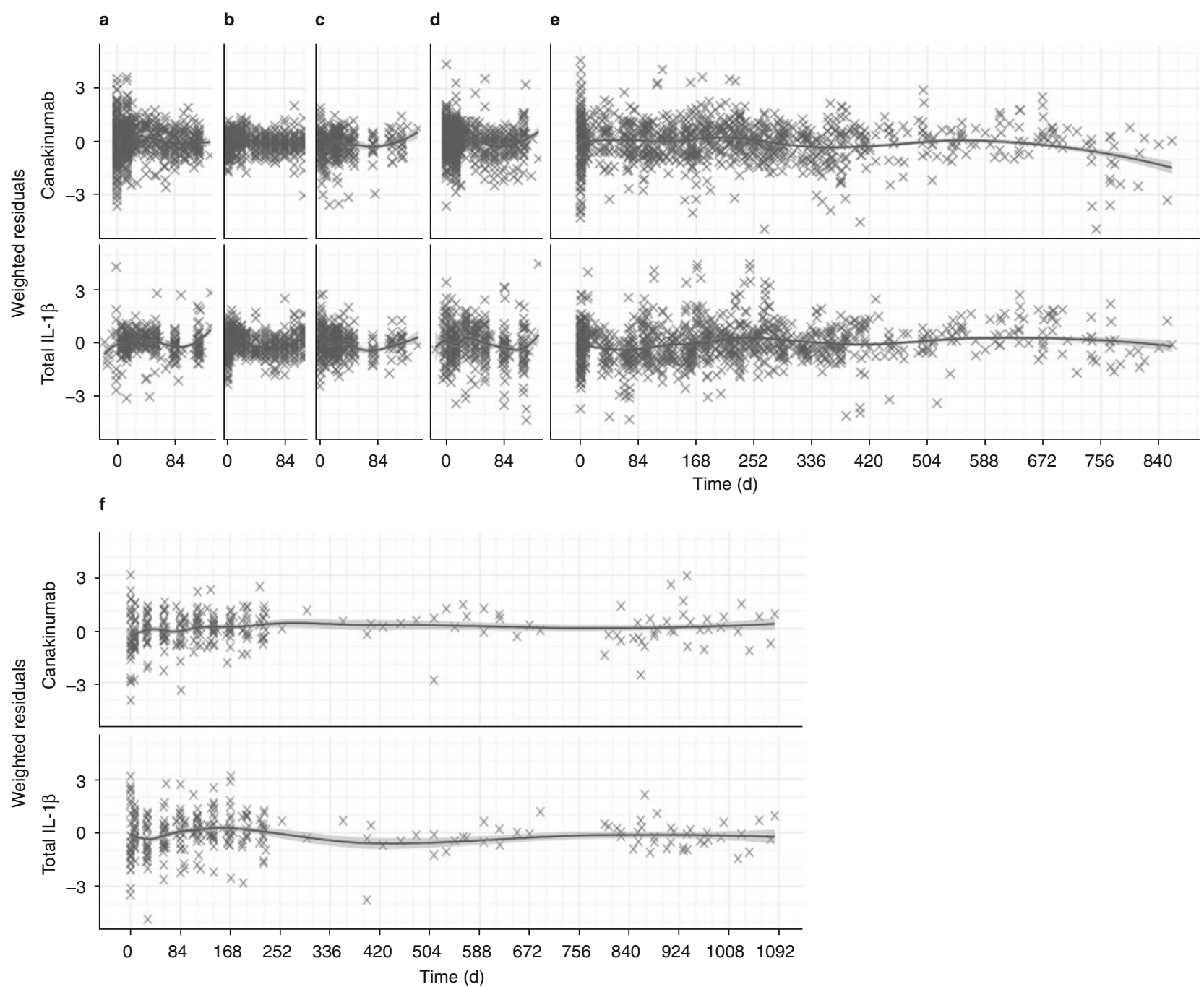

Fig. 6. Diagnostic plots from the population-based pharmacokinetic-binding model for canakinumab and interleukin-1 $1 \beta$ : NONMEM ${ }^{\circledR}$ weighted residuals vs time for each study. The study populations are taken from six studies: (a) study CACZ885B2101 ${ }^{[12]}$ (healthy subjects and asthmatic patients); (b) study CACZ885A1101 (NCT00421226) ${ }^{[13]}$ [Japanese healthy subjects]; (c) study CAZC885A2202[15] (psoriasis patients); (d) study CACZ885A2101 (NCT00619905) $^{[14]}$ (rheumatoid arthritis patients); (e) study CACZ885A2102 (NCT00487708) ${ }^{[16]}$ [cryopyrin-associated periodic syndromes; phase II]; and (f) study CACZ885D2304 (NCT00465985) ${ }^{[11]}$ [cryopyrin-associated periodic syndromes; phase III]. 
Table IV. Population pharmacokinetic-binding model estimated parameters

\begin{tabular}{|c|c|c|c|}
\hline Parameter (units) & $\begin{array}{l}\text { Population mean } \\
{[\theta \pm S E \text { of } \theta]}\end{array}$ & $\begin{array}{l}\text { Interindividual variance } \\
{[\eta \pm S E \text { of } \eta(C V)]}\end{array}$ & Shrinkage (\%) \\
\hline \multicolumn{4}{|l|}{ Canakinumab } \\
\hline \multicolumn{4}{|c|}{$\mathrm{CL}_{\mathrm{D}}(\mathrm{L} / \mathrm{d}$ at $70 \mathrm{~kg}$ and $43 \mathrm{~g} / \mathrm{L}$ albumin $)$} \\
\hline CAPS & $0.174 \pm 0.0124$ & $0.0859 \pm 0.0147(29 \%)$ & 4.64 \\
\hline Caucasian HV & $0.137 \pm 0.00657$ & & \\
\hline Japanese HV & $0.169 \pm 0.00855$ & & \\
\hline RA & $0.195 \pm 0.00883$ & & \\
\hline Asthma & $0.168 \pm 0.0104$ & & \\
\hline Psoriasis & $0.185 \pm 0.0146$ & & \\
\hline $\mathrm{V}_{\mathrm{C}}(\mathrm{L}$ at $70 \mathrm{~kg})$ & $3.30 \pm 0.135$ & $0.0589 \pm 0.0205(24 \%)$ & 21.0 \\
\hline$V_{P}(L$ at $70 \mathrm{~kg})$ & $2.71 \pm 0.151$ & $0.0817 \pm 0.0200(29 \%)$ & 30.9 \\
\hline $\mathrm{PS}_{\mathrm{D}}(\mathrm{L} / \mathrm{d})$ & $0.429 \pm 0.0529$ & $0.280 \pm 0.107(53 \%)$ & 36.0 \\
\hline \multicolumn{4}{|c|}{$k_{a}\left(d^{-1}\right.$ for 34 year old $)$} \\
\hline NSO cell line & $0.299 \pm 0.0382$ & $0.406 \pm 0.107(64 \%)$ & 13.8 \\
\hline Sp2/0 cell line & $0.269 \pm 0.0634$ & & \\
\hline \multicolumn{4}{|l|}{$\mathrm{F} 1$} \\
\hline NSO cell line & $63.3 \% \pm 5.26 \%^{\mathrm{a}}$ & & \\
\hline Sp2/0 cell line & $70.0 \% \pm 8.25 \%^{a}$ & & \\
\hline \multicolumn{4}{|l|}{ IL-1 $\beta$} \\
\hline \multicolumn{4}{|l|}{$\mathrm{CL}_{\mathrm{L}}(\mathrm{L} / \mathrm{d})$} \\
\hline CAPS & $14.2 \pm 2.55$ & $0.371 \pm 0.0800(61 \%)$ & 26.9 \\
\hline Caucasian HV & $13.5 \pm 4.17$ & & \\
\hline Japanese HV & $31.0 \pm 13.9$ & & \\
\hline RA & $22.9 \pm 2.89$ & & \\
\hline Asthma & $24.9 \pm 5.16$ & & \\
\hline Psoriasis & $19.0 \pm 4.70$ & & \\
\hline \multicolumn{4}{|l|}{$\mathrm{R}_{\mathrm{LI}}(\mathrm{ng} / \mathrm{d})$} \\
\hline CAPS & $9.57 \pm 1.34$ & $0.261 \pm 0.0464(51 \%)$ & 10.0 \\
\hline Caucasian HV & $4.50 \pm 0.428$ & & \\
\hline Japanese HV & $4.72 \pm 0.344$ & & \\
\hline RA & $8.06 \pm 0.876$ & & \\
\hline Asthma & $6.18 \pm 0.467$ & & \\
\hline Psoriasis & $7.19 \pm 1.08$ & & \\
\hline \multicolumn{4}{|l|}{$\mathrm{K}_{\mathrm{D}}(\mathrm{nmol} / \mathrm{L})$} \\
\hline CAPS & $1.07 \pm 0.173$ & $0.395 \pm 0.130(63 \%)$ & 28.8 \\
\hline Caucasian HV & $1.01 \pm 0.283$ & & \\
\hline Japanese HV & $0.354 \pm 0.161$ & & \\
\hline RA & $0.227 \pm 0.0658$ & & \\
\hline Asthma & $0.543 \pm 0.125$ & & \\
\hline Psoriasis & $0.360 \pm 0.0952$ & & \\
\hline $\mathrm{PS}_{\mathrm{L}}(\mathrm{L} / \mathrm{d})$ & $0.386 \pm 0.0555$ & $0.254 \pm 0.139(50 \%)$ & 45.2 \\
\hline
\end{tabular}


Table IV. Contd

\begin{tabular}{lll}
\hline Parameter (units) & $\begin{array}{l}\text { Population mean } \\
{[\theta \pm S E \text { of } \theta]}\end{array}$ & $\begin{array}{l}\text { Interindividual variance } \\
{[\eta \pm S E \text { of } \eta(C V)]}\end{array}$ \\
\hline Covariates & $0.695 \pm 0.0900$ \\
Weight on $\mathrm{CL}_{\mathrm{D}}{ }^{\mathrm{b}}$ & $-0.916 \pm 0.185$ \\
Albumin on $\mathrm{CL}_{\mathrm{D}}{ }^{\mathrm{b}}$ & $0.684 \pm 0.0921$ \\
Weight on $\mathrm{V}_{\mathrm{C}}^{\mathrm{b}}$ & $0.798 \pm 0.236$ \\
Weight on $\mathrm{V}_{\mathrm{P}}^{\mathrm{b}}$ & $-0.555 \pm 0.151$ \\
Age on $\mathrm{k}_{\mathrm{a}}^{\mathrm{b}}$ & \\
Residual error variances $\left[\boldsymbol{\sigma}^{2} \pm \mathrm{SE}(\mathrm{CV})\right]$ & $0.0527 \pm 0.00572(23 \%)$ \\
Canakinumab & $0.0840 \pm 0.0113(29 \%)$ & 7.58 \\
$\mathrm{IL}-1 \beta$ & 10.3 \\
\hline
\end{tabular}

a Estimated on the logit scale with mean and SE back-calculated by simulation.

b Exponent for power model on centred covariate.

CAPS = cryopyrin-associated periodic syndromes; $\mathbf{C L}_{\mathbf{D}}=$ clearance for drug; $\mathbf{C L}_{\mathbf{L}}=$ clearance for ligand; $\mathbf{C V}=$ coefficients of variation; $\mathbf{F} 1=$ subcutaneous bioavailability; $\mathbf{H V}=$ healthy volunteers; $\mathbf{I L}=$ interleukin; $\mathbf{K}_{\mathbf{a}}=$ absorption rate; $\mathbf{K}_{\mathbf{D}}=$ binding dissociation constant between drug and ligand; $\mathbf{P S} \mathbf{S}_{\mathbf{D}}=$ intercompartmental permeability-surface area coefficient for drug; $\mathbf{P S}_{\mathbf{L}}=$ intercompartmental permeability-surface area coefficients for ligand; $\mathbf{R A}=$ rheumatoid arthritis patients; $\mathbf{R}_{\mathrm{LI}}=$ production rate of ligand; $\mathbf{S E}=$ standard error; $\mathbf{V}_{\mathbf{C}}=$ central volume; $\mathbf{V}_{\mathbf{P}}=$ peripheral volume .

directed against cell-surface antigens often exhibit nonlinear pharmacokinetic behaviour while antibodies (such as canakinumab) directed against soluble receptors (e.g. soluble IL-1 $\beta$ ) exhibit linear behaviour. ${ }^{[27]}$

\section{Pharmacokinetics after Repeated Administration}

Canakinumab exhibits dose- and time-independent pharmacokinetics. In five of the six studies listed in table I, multiple doses of canakinumab were administered, thus allowing for the assessment of canakinumab pharmacokinetics after repeated administration; long-term pharmacokinetic and pharmacodynamic assessments were performed in two of the CAPS trials, ${ }^{[1,16]}$ with some patients exposed to canakinumab treatment for 9 months to over 2 years. There was no evidence of time-dependent alteration of the pharmacokinetic profile of canakinumab in any of the studies. Figure 6 shows a plot of the weighted residuals (the normalized difference between the observed and predicted concentrations from the population pharmacokinetic-binding model) versus time for canakinumab and total IL-1 $\beta$. The pharmacokinetic-binding model includes an assumption of time-invariance of the pharmacokinetic parameters; thus, any drift in the residuals in a positive or negative direction would indicate that this is an invalid assumption. The residuals were randomly distributed around the zero value and showed no directional shift in the plot.

The time to steady state was estimated to be approximately 130 days ( $~ 5$ half-lives), with accumulation of approximately 1.3-fold for a subcutaneous dosing regimen administered every 8 weeks in a typical adult CAPS patient weighing $70 \mathrm{~kg}$.
None of the patients in the two CAPS studies showed a treatment-induced immune response to canakinumab that can alter the pharmacokinetic properties of canakinumab.

\subsubsection{In Vivo Binding Properties of Canakinumab}

IL-1 $\beta$ at baseline prior to initiation of canakinumab treatment could not be detected in the majority of patients, including CAPS patients. This is in contrast to the detection of total IL-1 $\beta$ following administration of canakinumab in all groups including healthy subjects and patients. The apparent paradox of not observing elevated IL-1 $\beta$ in the majority of the CAPS

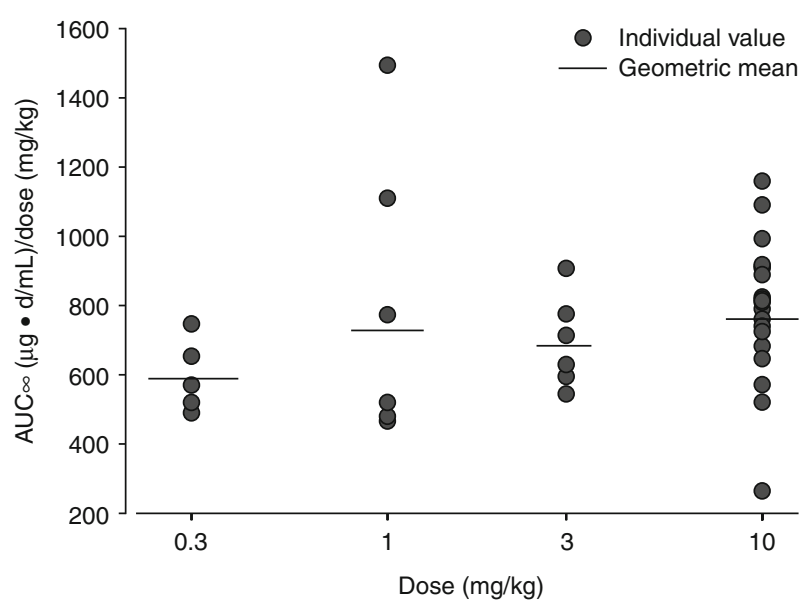

Fig. 7. Dose-normalized area under the serum concentration-time curve following intravenous administration of canakinumab $0.3-10 \mathrm{mg} / \mathrm{kg}$ vs dose in rheumatoid arthritis patients. The data are taken from study CACZ885A2101 (NCT00619905). ${ }^{[14]} \mathbf{A U C}_{\infty}=$ area under the serum concentration-time curve from time 0 to infinity. 


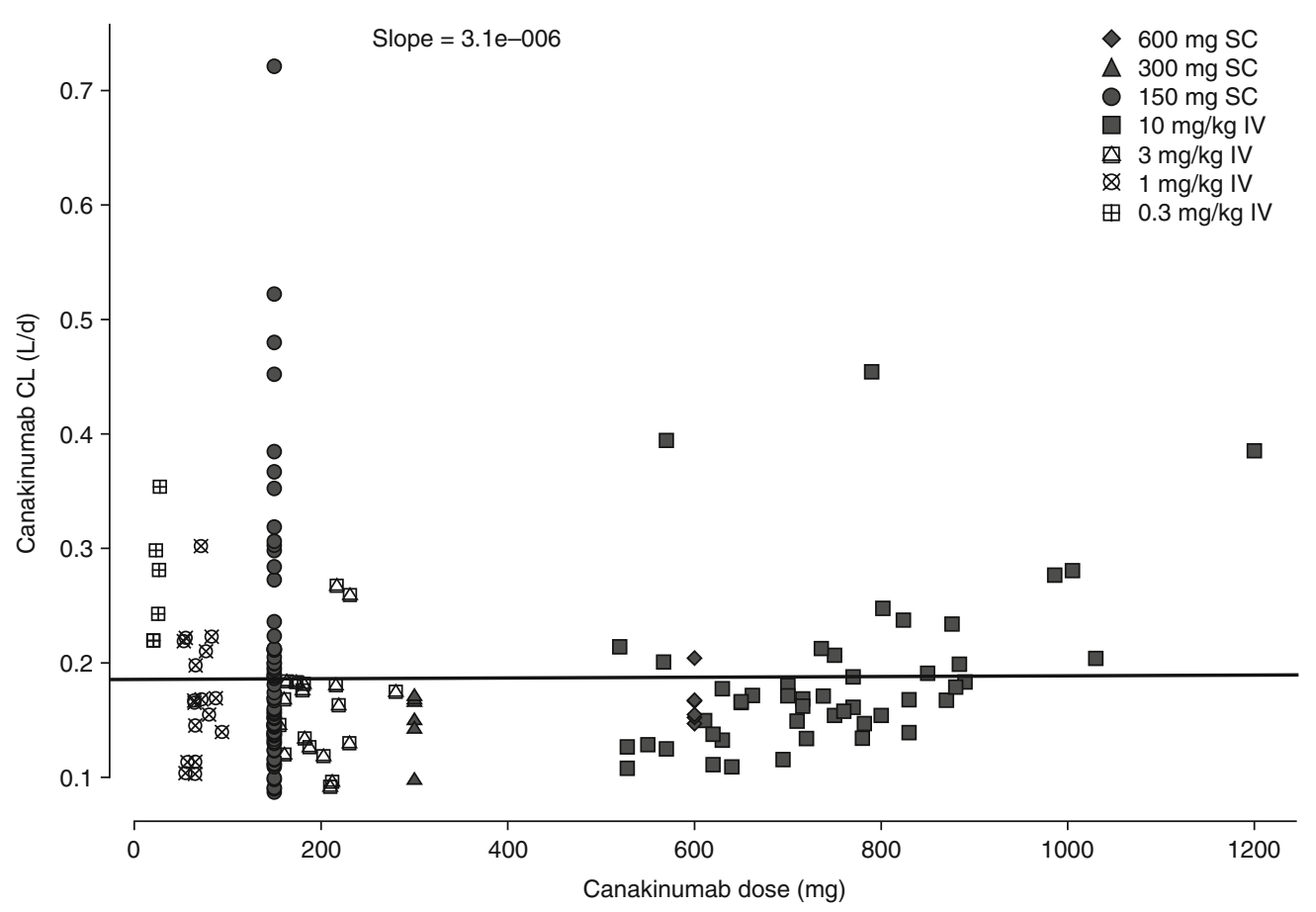

Fig. 8. Canakinumab serum clearance (estimated by the pharmacokinetic-binding model) vs dose. $\mathbf{C L}=$ serum clearance; $\mathbf{I V}=$ intravenous; $\mathbf{S C}=$ subcutaneous.

patients despite the fact that IL- $1 \beta$ is produced in excess may be explained by:

1. the fact that free IL-1 $\beta$ is rapidly cleared from circulation; ${ }^{[28]}$ and

2. that even a high production rate in tissues may not lead to a measurable increase in IL-1 $\beta$ levels in serum.

The IL-1 $\beta$ in subjects including CAPS patients is only quantifiable when the clearance of IL- $1 \beta$ is decreased by binding to the human anti- IL-1 $\beta$ antibody (i.e. canakinumab).

Total IL-1 $\beta$ concentrations increased following canakinumab dosing in patients, including CAPS patients (figure 1) as well as healthy subjects (figure 2). The population estimate of the apparent $K_{D}$ for the binding of canakinumab to IL-1 $\beta$ in CAPS patients was $1.07 \pm 0.173 \mathrm{nmol} / \mathrm{L}$ (table IV). As expected, this value differed from the in vitro $\mathrm{K}_{\mathrm{D}}$ value; systemspecific factors such as production and elimination rate of endogenous IL- $1 \beta$, a dynamic system with a changing distribution equilibrium between tissues and blood compartment, and competition with other IL-1 $\beta$ binding entities such as soluble receptors may explain the differences between the in vivo and in vitro $\mathrm{K}_{\mathrm{D}}$ estimates. The estimated population means for $\mathrm{K}_{\mathrm{D}}$ were $1.07 \mathrm{nmol} / \mathrm{L}$ in adult CAPS patients, $0.543 \mathrm{nmol} / \mathrm{L}$ in adult asthma patients, $0.227 \mathrm{nmol} / \mathrm{L}$ in adult RA patients, $0.360 \mathrm{nmol} / \mathrm{L}$ in adult psoriasis patients, $1.01 \mathrm{nmol} / \mathrm{L}$ in healthy subjects of mostly Caucasian descent and $0.354 \mathrm{nmol} / \mathrm{L}$ in healthy Japanese volunteers (table IV).
$\mathrm{R}_{\mathrm{LI}}$ also varied with study population, being greatest in CAPS patients at $9.57 \mathrm{ng} / \mathrm{day}$. The other study populations had IL- $1 \beta$ production rates that ranged from 4.5 to $8.06 \mathrm{ng} /$ day.

\section{Effect of Demographic Characteristics and Extrinsic Factors}

The effect of various covariates on the pharmacokinetic and binding properties of canakinumab was explored primarily with the population pharmacokinetic-binding model as well as through comparison of non-compartmental pharmacokinetic parameters across studies in various patient populations. A brief summary of the findings are presented in this section.

\subsection{Age and Body Weight}

Based on the population model, age (range 4-74 years) did not impact any key pharmacokinetic parameters (serum clearance, $\mathrm{V}_{\mathrm{C}}$ and $\mathrm{V}_{\mathrm{P}}$ ) after correction for body weight. Body weight is the most significant covariate influencing canakinumab exposure, a phenomenon commonly observed for most other monoclonal antibodies. ${ }^{[29]}$

The serum clearance and volumes of canakinumab were centred on the median body weight of $70 \mathrm{~kg}$ in the CAPS population and increased with body weight (WT [in $\mathrm{kg}]$ ), as 
described by an allometric relationship (equation 10):

$$
\theta=\theta_{70 \mathrm{~kg}} \bullet(\mathrm{WT} / 70)^{\exp }
$$

where $\theta$ is the parameter $\left(\mathrm{CL}_{\mathrm{D}}, \mathrm{V}_{\mathrm{C}}, \mathrm{V}_{\mathrm{P}}\right)$; and exp is the allometric exponent $(0.70,0.68$ and 0.80 , respectively). The estimated coefficients for serum clearance and $V_{P}$ were not significantly different from the general scaling relationships of 0.75 and 1, respectively, ${ }^{[30-32]}$ although there was a slight deviation from proportionality for the central volume. The exponent value of less than 1 for the clearance-body weight relationship generally signifies a faster rate of clearance in smaller children than in adults, relative to their body weight.

Additionally, $\mathrm{k}_{\mathrm{a}}$ appeared to slow with age, with a 1.5 -fold decrease in the rate constant when age doubles.

\subsection{Renal Function}

As canakinumab is a human IgG immunoglobulin with large molecular size $(\sim 150 \mathrm{kDa})$, impairment of renal function is not likely to influence the pharmacokinetics of canakinumab. This was supported by the (non-compartmental) clearance and $\mathrm{C}_{\max }$ values of the four CAPS patients with moderate to end-stage renal insufficiency: $\mathrm{CL} / \mathrm{F}$ following the initial $150 \mathrm{mg}$ subcutaneous dose was $0.230,0.246,0.196$ and $0.217 \mathrm{~L} /$ day, similar to the mean adult $\mathrm{CL} / \mathrm{F}$ value of $0.228 \mathrm{~L} /$ day observed in the phase II clinical study in CAPS patients (table III). $\mathrm{C}_{\max }$ values were $20.7,13.3,11.1$ and $11.7 \mu \mathrm{g} / \mathrm{mL}$, also close to the mean adult $\mathrm{C}_{\max }$ value of $15.9 \mu \mathrm{g} / \mathrm{mL}$.

\subsection{Sex}

Data from 135 males and 98 females were included in the population pharmacokinetic analysis. No sex-related difference was apparent in any of the pharmacokinetic or binding parameters (e.g. serum clearances in male and female subjects were 0.186 and $0.176 \mathrm{~L} /$ day, respectively).

\subsection{Patient Population}

Pharmacokinetic parameters were generally comparable across the healthy subjects and patient populations. As summarized in table III, the average serum clearance (based on non-compartmental analysis of each treatment arm) following intravenous administration ranged from 0.120 to $137,0.160$ to $0.174,0.200$ to $0.283,0.156$ and $0.182 \mathrm{~L} /$ day in healthy Caucasian subjects, healthy Japanese subjects, RA patients, mild asthmatics and CAPS patients, respectively; similar values for clearance were estimated for each population by the phar- macokinetic-binding model (table IV). The mean for the noncompartmental estimates of $t_{1 / 2}$ in adult CAPS patients, psoriatic patients and in healthy adult Japanese subjects following a single subcutaneous dose of canakinumab $150 \mathrm{mg}$ were 26.1, 26.2 and 26.3 days, respectively. Similarly, the population pharmacokinetic-binding model results found no clinically relevant differences in pharmacokinetic properties of canakinumab between the patient populations.

\subsection{Drug-Drug Interactions}

No clinical drug interaction studies between canakinumab and other medicinal products have been performed. The most common concomitant medications in CAPS patients are paracetamol, NSAIDs, systemic corticosteroids, antibacterials (cephalosporin, amoxicillin) and iron supplements. It is not expected that these medications influence the pharmacokinetics of canakinumab. This is mainly because monoclonal antibodies are not metabolized by the cytochrome P450 (CYP) system, and their mechanism of elimination could be via catabolism, different from metabolic or renal pathways of elimination for small molecules. In the RA patients where canakinumab is administered along with ongoing methotrexate treatment, the canakinumab pharmacokinetic parameters did not differ from those collected from other studies, signifying that canakinumab pharmacokinetics was unaffected when coadministered with methotrexate.

However, there is a theoretical potential for the existence of less obvious pathways of interaction. Inflammatory disease states can modulate drug pharmacokinetic properties through alterations of levels of drug-metabolizing enzymes. Specifically, the formation of CYP enzymes is suppressed by increased levels of proinflammatory cytokines (e.g. IL-1, IL-6, tumour necrosis factor- $\alpha$ ) during chronic inflammation. ${ }^{[33-35]}$ Anti-cytokine antibodies that target and neutralize these proinflammatory cytokines or their receptors are capable of restoration of CYP enzymes to normal levels. ${ }^{[36]}$ Molecules that bind to IL-1, such as canakinumab, can be expected to indirectly restore the expression of CYP enzymes to normal levels. Therefore, there is a possibility of drug interactions with a biologic that reverses an inflammatory condition, thus upregulating levels of CYPs and resulting in increased clearance of coadministered drugs that are CYP substrates.

\subsection{Other Factors}

Lower levels of serum albumin correlate with higher serum clearance for canakinumab (equation 11):

$$
\mathrm{CL}_{\mathrm{D}}=\mathrm{CL}_{\mathrm{D} 70 \mathrm{~kg}} \bullet(\text { albumin } / 43)^{-0.92}
$$


where the median serum albumin level is $43 \mathrm{~g} / \mathrm{L}$. This correlation may be due to the fact that both proteins are rescued from reticuloendothelial elimination by the Brambell or FcRn receptor.

\section{Biocomparability}

During the development of canakinumab a cell line switch from NS0 to Sp2/0 was implemented. In the early clinical development studies, including the first CAPS study, ${ }^{[16]}$ canakinumab was derived from an NS0 cell line. Table V summarizes the supporting pharmacokinetic comparability data addressing the cell line switch from NS0 to Sp2/0 during canakinumab development.

Non-clinical pharmacokinetic comparability was demonstrated between canakinumab derived from the NS0 and Sp2/0 cell lines in a 2-way single-dose ( $5 \mathrm{mg} / \mathrm{kg}$ subcutaneous) pharmacokinetic crossover study in marmosets. The ratio of means of the pharmacokinetic parameters (AUC and $\mathrm{C}_{\max }$ ) of $\mathrm{Sp} 2 / 0$ derived canakinumab with reference to NS0-derived canakinumab ranged from $104 \%$ to $107 \%$, suggesting a lack of pharmacokinetic differences in marmosets. Upon successful demonstration of non-clinical comparability, the new drug material derived from the $\mathrm{Sp} 2 / 0$ cell line was introduced in the first phase III trial in CAPS patients. ${ }^{[11]}$

A model-based comparison of the two product types in humans allowed for the estimation of bioavailability of the new material relative to the previous drug material (table V). Canakinumab pharmacokinetic parameters were comparable between the two cell types, in line with the results from the marmoset bridging study. The relative bioavailability of the $\mathrm{Sp} 2 / 0$ material with reference to the NS0 material was $110 \pm 6 \%$, indicating comparable bioavailability. In addition, an increase in total IL-1 $\beta$ was observed irrespective of the drug form used, indicating capture of the ligand (IL-1 $\beta$ ) by canakinumab derived from these two cell lines.

\section{Clinical Efficacy of Canakinumab}

Canakinumab treatment was effective in achieving a fast, complete and sustained response (i.e. effective prevention of disease flare) in adult and paediatric CAPS patients. ${ }^{[16]}$ Acutephase serum inflammatory protein markers (CRP and SAA, as well as serum levels of IL-6 and IL-1 receptor antagonist), white blood cell counts, neutrophils and platelet counts supported the clinical observations as they rapidly reached normal levels following canakinumab injection.

In the same study, ${ }^{[16]}$ relapse of symptoms were shown to be closely related to serum canakinumab concentrations. A pharmacokinetic-flare probability model was developed using data from four CAPS patients with the objective of identifying a dosing regimen to minimize the probability of flare during canakinumab treatment. ${ }^{[16]}$ Simulations of various dosing regimens were performed from the final model, and the regimen of subcutaneous canakinumab $150 \mathrm{mg}$ every 8 weeks was selected; this regimen was predicted to give less than a $1 \%$ probability of relapse once patients were brought to steady-state, and $3 \%$ chance of flare at the end of the first dosing cycle. This regimen was used in the randomized placebo-controlled study with a total of 31 patients. ${ }^{[11]}$ Results from the study showed that within a

Table V. Comparability exercises and the canakinumab pharmacokinetic parameters of the pre- and post-change material for the cell line switch

\begin{tabular}{|c|c|c|c|}
\hline Parameter & NSO & & $\mathrm{Sp} 2 / 0$ \\
\hline Drug substance concentration & $\geq 52 \mathrm{mg} / \mathrm{mL}$ & & $\geq 65 \mathrm{mg} / \mathrm{mL}, \geq 180 \mathrm{mg} / \mathrm{mL}$ \\
\hline Drug substance manufacturing scale (approximate working volume) & $220 \mathrm{~L}, 1100 \mathrm{~L}$ & & $11000 \mathrm{~L}$ \\
\hline \multicolumn{4}{|l|}{ Marmoset pharmacokinetic comparability } \\
\hline$t_{1 / 2}$ (days) & $7.07 \pm 1.83^{\mathrm{a}}$ & & $6.33 \pm 1.91^{\mathrm{a}}$ \\
\hline $\mathrm{C}_{\max }(\mu \mathrm{g} / \mathrm{mL})$ & & $1.07(0.90,1.26)^{\mathrm{b}}$ & \\
\hline$A \cup C_{\text {last }}(\mu \mathrm{g} \bullet \mathrm{day} / \mathrm{mL})$ & & $1.04(0.90,1.21)^{b}$ & \\
\hline $\mathrm{AUC}_{\infty}(\mu \mathrm{g} \bullet \mathrm{day} / \mathrm{mL})$ & & $1.04(0.91,1.20)^{\mathrm{b}}$ & \\
\hline \multicolumn{4}{|l|}{ Human pharmacokinetic comparability ${ }^{\mathrm{C}}$} \\
\hline Relative bioavailability & & $1.10(0.996,1.20)^{b}$ & \\
\hline
\end{tabular}

a Mean \pm SD.

b Values are expressed as geometric mean ratio (reference: NS0; test: Sp2/0) [90\% Cl].

c From the pharmacokinetic-binding model.

$\mathbf{A} \mathbf{U} \mathbf{C}_{\infty}=$ area under the serum concentration-time curve from time 0 to infinity; $\mathbf{A U C}_{\text {last }}=$ area under the serum concentration-time curve from time 0 to the last measurable concentration sampling time; $\mathbf{C}_{\max }=$ maximum (peak) serum concentration; $\mathbf{S D}=$ standard deviation; $\mathbf{t}_{1 / 2}=$ elimination half-life. 
period of 24 weeks, all patients randomized to canakinumab remained disease free, whereas $81 \%$ of patients on placebo flared, thus supporting $150 \mathrm{mg}$ every 8 weeks as an effective dosing regimen.

In addition, the long $t_{1 / 2}$ of canakinumab of approximately 4 weeks supports the use of an every 8 -week dosing regimen in CAPS patients. This compares favourably with the shorter $t_{1 / 2}$ of other anti-IL-1 $\beta$ agents, such as anakinra (4-6 hours) ${ }^{[37]}$ and rilonacept $\left(\sim 1\right.$ week) ${ }^{[38]}$ Canakinumab, with dosing only every 8 weeks, thus represents a major step forward in the management of CAPS when compared with the currently available IL-1 $\beta$-targeted alternate treatments.

\section{Safety Assessments of Canakinumab}

The overall safety of canakinumab as assessed in completed and ongoing clinical trials demonstrates a good tolerability profile, as evidenced by very few discontinuations, few injection site reactions, a slightly increased rate of non-serious infections of the upper respiratory tract, and reported events of vertigo in CAPS patients that were no more frequent than the rate in prior medical histories. The safety and tolerability of canakinumab demonstrated in the two CAPS trials ${ }^{[11,16]}$ were further confirmed in a long-term phase III study evaluating the safety and efficacy of canakinumab in CAPS patients of different severity phenotypes. ${ }^{[39]}$

Anti-canakinumab antibodies in serum were measured by surface plasmon resonance spectroscopy using a sensitive and validated Biacore ${ }^{\circledR}$ binding assay. None of the subjects treated with canakinumab in the six different clinical studies developed anticanakinumab antibodies, as measured by the Biacore ${ }^{\circledR}$ binding assay, indicating a low-immunogenic potential of canakinumab.

\section{Conclusions}

Canakinumab has the expected pharmacokinetic properties typical of human IgG-type immunoglobulins, such as slow serum clearance and a low $\mathrm{V}_{\mathrm{ss}}$. Canakinumab has high absolute subcutaneous bioavailability (70\%) and a long $t_{1 / 2}$ of approximately 4 weeks. Canakinumab exhibits dose-proportional and time-independent pharmacokinetics; there is no evidence of accelerated clearance or time-dependent changes in the pharmacokinetics following repeated administration. The pharmacokinetics of canakinumab in various disease states (e.g. CAPS, RA, psoriasis or asthma) are comparable to those in healthy individuals. No sex- or age-related pharmacokinetic differences were observed after correction for a patient's body weight.
The ability of canakinumab to capture and thereby reduce levels of free IL-1 $\beta$ was demonstrated in all clinical studies, irrespective of the type of population. An increase in total IL-1 $\beta$ concentrations was observed after canakinumab dosing, indicating the binding of IL-1 $\beta$ by canakinumab; this binding leads to the blockage of downstream events of IL- $1 \beta$ signalling, including IL-1 $\beta$ production, IL-1 $\beta$ pathway-related gene activation, e.g. elevation of acute phase proteins such as SAA and CRP, and mobilization of neutrophils and platelets from bone marrow. As a result, canakinumab demonstrates convincing evidence of efficacy in IL-1 $\beta$-driven inflammatory diseases such as CAPS.

\section{Acknowledgements}

During the early development of this manuscript, Dr Christiane Rordorf unfortunately passed away. However, considering her significant involvement to the work presented in this manuscript, we feel it is appropriate to acknowledge her contribution by retaining her name in the list of authors.

The authors acknowledge the support of Aurélie Gautier, Novartis Pharma AG (Basel, Switzerland) and David A. James, Novartis Pharmaceuticals Corporation (East Hanover, NJ, USA) for their support in programming the datasets used for the model-based analyses and for various calculations on the data. We also acknowledge the support of Ajithkumar Vasudevan, Novartis Healthcare Private Ltd (Hyderabad, India) for editorial assistance.

The studies described in this review were funded by Novartis Pharmaceutical Corporation.

Conflicts of interest: Abhijit Chakraborty, Philip J. Lowe, David Floch, Hermann Gram and Sandip Roy are employees of Novartis. Stacey Tannenbaum was also an employee of Novartis when this review was prepared, and is currently an employee of Astellas Pharma Global Development (Deerfield, IL, USA). Abhijit Chakraborty and Sandip Roy own Novartis stock, and Philip J. Lowe owns Novartis stock and stock options.

\section{References}

1. Agostini L, Martinon F, Burns K, et al. NALP3 forms an IL-1beta-processing inflammasome with increased activity in Muckle-Wells autoinflammatory disorder. Immunity 2004; 20: 319-25

2. Aksentijevich I, Nowak M, Mallah M, et al. De novo CIAS1 mutations, cytokine activation, and evidence for genetic heterogeneity in patients with neonatal-onset multisystem inflammatory disease (NOMID): a new member of the expanding family of pyrin-associated autoinflammatory diseases. Arthritis Rheum 2002; 46: 3340-8

3. Hoffman HM, Rosengren S, Boyle DL, et al. Prevention of cold-associated acute inflammation in familial cold autoinflammatory syndrome by interleukin-1 receptor antagonist. Lancet 2004; 364: 1779-85

4. Pascual V, Allantaz F, Arce E, et al. Role of interleukin-1 (IL-1) in the pathogenesis of systemic onset juvenile idiopathic arthritis and clinical response to IL-1 blockade. J Exp Med 2005; 201: 1479-86

5. Bresnihan B, Alvaro-Gracia JM, Cobby M, et al. Treatment of rheumatoid arthritis with recombinant human interleukin-1 receptor antagonist. Arthritis Rheum 1998; 41: 2196-204 
6. So A, De Smedt T, Revaz S, et al. A pilot study of IL-1 inhibition by anakinra in acute gout. Arthritis Res Ther 2007; 9: R28

7. de Kluijver J, Grunberg K, Pons D, et al. Interleukin-1beta and interleukin-1 ra levels in nasal lavages during experimental rhinovirus infection in asthmatic and non-asthmatic subjects. Clin Exp Allergy 2003; 33: 1415-8

8. Rupp J, Kothe H, Mueller A, et al. Imbalanced secretion of IL-1beta and IL1RA in Chlamydia pneumoniae-infected mononuclear cells from COPD patients. Eur Respir J 2003; 22: 274-9

9. Debets R, Hegmans JP, Troost RJ, et al. Enhanced production of biologically active interleukin-1 alpha and interleukin- 1 beta by psoriatic epidermal cells ex vivo: evidence of increased cytosolic interleukin-1 beta levels and facilitated interleukin-1 release. Eur J Immunol 1995; 25: 1624-30

10. Larsen CM, Faulenbach M, Vaag A, et al. Interleukin-1-receptor antagonist in type 2 diabetes mellitus. N Engl J Med 2007; 356: 1517-26

11. Lachmann HJ, Kone-Paut I, Kuemmerle-Deschner JB, et al. Use of canakinumab in the cryopyrin-associated periodic syndrome. N Engl J Med 2009; 360: $2416-25$

12. Bonner J, Lloyd P, Lowe $\mathrm{P}$, et al. PK/PD, safety and tolerability of a human anti-IL-1B monoclonal antibody (ACZ885) in healthy subjects [abstract no. 748]. Annual Congress of the European Respiratory Society; 2006 Sep 2-6; Munich

13. Novartis. Safety, tolerability, pharmacokinetics and pharmacodynamics of ACZ885 in healthy Japanese male volunteers [ClinicalTrials.gov identifier NCT00421226]. US National Institutes of Health, ClinicalTrials.gov [online]. Available from URL: http://www.clinicaltrials.gov [Accessed 2012 Apr 2]

14. Alten R, Gram H, Joosten LA, et al. The human anti-IL-1 beta monoclonal antibody ACZ885 is effective in joint inflammation models in mice and in a proof-of-concept study in patients with rheumatoid arthritis. Arthritis Res Ther 2008; 10: R67

15. A 4 week treatment study to evaluate the safety, tolerability, immunogenicity of single and multiple $150 \mathrm{mg}$ subcutaneous administration of ACZ885 in psoriasis patients [EudraCT identifier 2005-004119-31] European Clinical Trial Database, EudraCT [online]. Available from URL: https://eudract. ema.europa.eu/index.html [Accessed on 2012 Apr 3]

16. Lachmann HJ, Lowe P, Felix SD, et al. In vivo regulation of interleukin 1 beta in patients with cryopyrin-associated periodic syndromes. J Exp Med 2009; 206: 1029-36

17. Vugmeyster $Y$, Tian X, Szklut $P$, et al. Pharmacokinetic and pharmacodynamic modeling of a humanized anti-IL-13 antibody in naive and ascaris-challenged cynomolgus monkeys. Pharma Res 2009; 26: 306-15

18. Barnes LM, Bentley CM, Dickson AJ. Advances in animal cell recombinant protein production: GS-NS0 expression system. Cytotechnology 2000; 32: $109-23$

19. Shulman M, Wilde CD, Kohler G. A better cell line for making hybridomas secreting specific antibodies. Nature 1978; 276: 269-70

20. European Medicines Agency. Ilaris: summary of product characteristics [online]. Available from URL: http://www.ema.europa.eu/docs/en GB/doc ument_library/EPAR_-_Product_Information/human/001109/WC500031680. pdf [Accessed 2012 Apr 2]

21. FDA label information. Ilaris (canakinumab) [online]. Available from URL: http://www.accessdata.fda.gov/drugsatfda_docs/label/2009/125319s000lbl. pdf [Accessed 2011 Dec 1]

22. Mire-Sluis AR, Barrett YC, Devanarayan V, et al. Recommendations for the design and optimization of immunoassays used in the detection of host antibodies against biotechnology products. J Immunol Methods 2004; 289: 1-16

23. Boon L, Brok HP, Bauer J, et al. Prevention of experimental autoimmune encephalomyelitis in the common marmoset (Callithrix jacchus) using a chimeric antagonist monoclonal antibody against human CD40 is associated with altered B cell responses. J Immunol 2001; 167: 2942-9

24. Beal SL, Sheiner LB, Boeckmann AJ, et al. NONMEM users guide. Ellicott City (MD): Icon Development Solutions, 2009

25. Hayashi N, Tsukamoto Y, Sallas WM, et al. A mechanism-based binding model for the population pharmacokinetics and pharmacodynamics of omalizumab. Br J Clin Pharmacol 2006; 63: 548-61

26. Wang W, Wang EQ, Balthasar JP. Monoclonal antibody pharmacokinetics and pharmacodynamics. Clin Pharmacol Ther 2008; 84: 548-58

27. Mould DR, Sweeney KRD. The pharmacokinetics and pharmacodynamics of monoclonal antibodies: mechanistic modeling applied to drug development. Curr Opin Drug Discov Devel 2007; 10: 84-96

28. Kopp WC, Urba WJ, Rager HC, et al. Induction of interleukin 1 receptor antagonist after interleukin 1 therapy in patients with cancer. Clin Cancer Res 1996; 2: 501-6

29. Dirks NL, Meibohm B. Population pharmacokinetics of therapeutic monoclonal antibodies. Clin Pharmacokinet 2010; 49: 633-59

30. West GB, Brown JH, Enquist BJ. A general model for the origin of allometric scaling laws for biology. Science 1997; 276: 122-6

31. West GB, Brown JH, Enquist BJ. The fourth dimension of life: fractal geometry and allometric scaling of organisms. Science 1999; 284: 1677-9

32. Bouwmeester HJ, Anderson BJ, Tibboel D, et al. Developmental pharmacokinetics of morphine and its metabolites in neonates, infants and young children. Br J Anaesthesia 2004; 92: 208-17

33. Aitken AE, Morgan ET. Gene-specific effects of inflammatory cytokines on cytochrome P450 2C, 2B6 and 3A4 mRNA levels in human hepatocytes. Drug Metab Dispos 2007; 35: 1687-93

34. Sunman JA, Hawke RL, LeCluyse EL, et al. Kupffer cell-mediated IL-2 suppression of CYP3A activity in human hepatocytes. Drug Metab Dispos 2004; 32: $359-63$

35. Chaluvadi MR, Nyagode BA, Kinloch RD, et al. TLR4-dependent and -independent regulation of hepatic cytochrome P450 in mice with chemically induced inflammatory bowel disease. Biochem Pharmacol 2009; 77: 464-71

36. Ashino T, Arima Y, Shioda S, et al. Effect of interleukin-6 neutralization on cyp3a11 and metallothionein-1/2 expressions in arthritic mouse liver. Eur J Pharmacol 2007; 558: 199-207

37. Burger D, Dayer JM, Palmer G, et al. Is IL-1 a good therapeutic target in the treatment of arthritis? Best Pract Res Clin Rheumatol 2006; 20: 879-96

38. Hoffman HM. Rilonacept for the treatment of cryopyrin associated periodic syndromes (CAPS). Expert Opin Biol Ther 2009; 9 (4): 519-31

39. Kuemmerle-Deschner J, Hachulla E, Cartwright R, et al. Two-year results from an open-label, multicentre, phase III study evaluating the safety and efficacy of canakinumab in patients with cryopyrin-associated periodic syndrome across different severity phenotypes. Ann Rheum Dis 2011; 70: 2095-102

Correspondence: Abhijit Chakraborty, PhD, Novartis Institutes for BioMedical Research, One Health Plaza, East Hanover, NJ 07936-1080, USA.

E-mail: abhijit.chakraborty@novartis.com 